\title{
THE MACROECONOMICS OF SPECIFICITY
}

\author{
Ricardo J. Caballero \\ Mohamad L. Hammour
}

Working Paper 5757

\section{NATIONAL BUREAU OF ECONOMIC RESEARCH 1050 Massachusetts Avenue \\ Cambridge, MA 02138 \\ September 1996}

We are grateful to Giuseppe Bertola, Olivier Blanchard, Peter Diamond, and seminar participants at ECARE, LSE, IMF, MIT, NYU, OFCE, Wharton, Yale, and the NBER 1996 Summer Institute (EFCCL) for helpful comments. Caballero thanks the NSF for financial support. This paper is part of NBER's research program in Economic Fluctuations and Growth. Any opinions expressed are those of the authors and not those of the National Bureau of Economic Research.

(C) 1996 by Ricardo J. Caballero and Mohamad L. Hammour. All rights reserved. Short sections of text, not to exceed two paragraphs, may be quoted without explicit permission provided that full credit, including (C) notice, is given to the source. 


\title{
THE MACROECONOMICS OF SPECIFICITY
}

\begin{abstract}
Specific quasi-rents build up in a wide variety of economic relationships, and are exposed to opportunism unless fully protected by contract. The recognition that such contracts are often incomplete has yielded major insights into the organization of microeconomic exchange. Rent appropriation, we argue, also has important macroeconomic implications. Resources are underutilized, factor markets are segmented, production suffers from technological "sclerosis," job destruction is out of balance with creation, recessions are excessively sharp, and expansions run into bottlenecks. While, depending on the nature of the shock, expansions may require reinforcement or stabilization, recessions should always be softened. In the long run, institutions, such as those governing capital-labor relations, may evolve to alleviate the problem by balancing appropriation. Technology choice will also be affected, with the appropriated factor partially "excluding" the other from production to reduce appropriation - as manifested in the role capital-labor substitution played in the rise of European unemployment.
\end{abstract}

Ricardo J. Caballero

Department of Economics

Massachusetts Institute of Technology

E52-252g

Cambridge, MA 02139

and NBER

caball@mit.edu
Mohamad L. Hammour Capital Guidance, SARL 32, avenue Hoche 75008 Paris

FRANCE 


\title{
The Macroeconomics of Specificity
}

\author{
Ricardo J. Caballero Mohamad L. Hammour*
}

August 31, 1996

\begin{abstract}
Specific quasi-rents build up in a wide variety of economic relationships, and are exposed to opportunism unless fully protected by contract. The recognition that such contracts are often incomplete has yielded major insights into the organization of microeconomic exchange. Rent appropriation, we argue, also has important macroeconomic implications. Resources are underutilized, factor markets are segmented, production suffers from technological "sclerosis," job destruction is out of balance with creation, recessions are excessively sharp, and expansions run into bottlenecks. While, depending on the nature of the shock, expansions may require reinforcement or stabilization, recessions should always be softened. In the long run, institutions, such as those governing capital-labor relations, may evolve to alleviate the problem by balancing appropriation. Technology choice will also be affected, with the appropriated factor partially "excluding" the other from production to reduce appropriation - as manifested in the role capital-labor substitution played in the rise of European unemployment.
\end{abstract}

\section{Introduction}

An asset is specific to a relationship to the extent that its value is greater within the relationship than outside. Economic specificity is a pervasive phenomenon. It arises when a firm selects and invests in a worker; when the worker spends his learning years in a firm; when capital is invested in a unionized firm or industry; when a bank extends credit to an entrepreneur; when an upstream firm makes investments to serve downstream customers; when foreign direct investment flows into a country.

*Respectively: MIT and NBER; Capital Guidance. We are grateful to Giuseppe Bertola, Olivier Blanchard, Peter Diamond, and seminar participants at ECARE, LSE, IMF, MIT, NYU, OFCE, Wharton, Yale, and the NBER 1996 Summer Institute (EFCCL) for helpful comments. Caballero thanks the NSF for financial support. 
Specificity in a relationship reduces the flexibility of separation decisions, which induces reluctance in the investment decision. This is the basic insight of the irreversible investment literature. But specificity acquires a potentially more troublesome dimension when combined with contracting difficulties. To the extent that it is irreversible, entering into a relationship creates specific quasi-rents that may not be divided ex post according to the parties' ex ante terms of trade. Avoiding this transformation from an ex ante competitive situation to an ex post bilateral monopoly - known in the literature as the "fundamental transformation" or the "holdup problem" - requires prior protection through comprehensive and enforceable long-term contracts. The problem is that such contracts are much closer to a methodological benchmark than a description of actual practices. ${ }^{1}$

Relationship specificity, together with the recognition of the difficulties involved in actual contracting, is a central building block in the modern economic theory of institutions (Klein, Crawford and Alchian 1978; Williamson 1979 and 1985). Specificity as a central dimension of transaction description forms the basis of insightful theories of the firm and internal organization (e.g., Grossman and Hart 1986; Hart and Moore 1990), of financial structure (e.g., Williamson 1988; Hart and Moore 1994; Shleifer and Vishny 1995), of public-choice institutions and credibility (e.g., North and Weingast 1989; Thomas and Worrall 1994), and a variety of other institutional arrangements. The common feature in those theories is the idea that a main function of institutional arrangements is to allow the transacting parties to partly circumvent the holdup problem.

The institutional literature generally acknowledges that, while institutions often help alleviate appropriability, they rarely resolve the problem fully. From a macroeconomic perspective, the prevalence of unprotected specific rents makes it a potentially central factor in determining the functioning of the aggregate economy. Transactions in the labor, capital,

\footnotetext{
${ }^{1}$ The problem of the appropriability of relationship-specific investment goes back early in the history of economic thought. Marx, in Das Capital, saw in it a channel for the capitalist exploitation of labor: "The knowledge, the judgement, and the will, which, though in ever so small degree, are practiced by the independent peasant or handicraftsman [...] - these faculties are now required only for the workshop as a whole. Intelligence in production expands in one direction, because it vanishes in many others. What is lost by the detail laborers, is concentrated in the capital that employs them [...]" (as cited by Rosenberg 1965).

Simons (1944) took the opposite view, that it is labor that takes advantage of specificity to approriate capital: "Frankly, I can see no reason why strongly organized workers, in an industry where huge investment is already sunk in highly durable assets, should ever permit a return on investment sufficient to attract new capital or even to induce full maintenance of existing capital." He provided an early analysis of the resulting under-investment: "[t]he bias against new investment inherent in labor organization is important [...]. Investors now face [...] the prospect that labor organizations will appropriate most or all of the earnings [...]. Indeed, every new, long-term commitment of capital is now a matter of giving hostages to organized sellers of complementary services."
} 
or goods markets are frequently characterized by some degree of specificity. The creation of a job, for example, typically involves relationship-specific investments by the firm and the worker (e.g., Becker 1964). Beyond its purely technological aspect, effective specificity may be increased by such institutional features as dismissal regulations (which devalue the firm's option of using its investment outside the relationship) or unionization (which narrows the firm's outside option to a sector outside the scope of the union). In partial equilibrium, unresolved opportunism results in reduced investment incentives, because the resulting specific quasi-rents may later be partly appropriated by others (e.g., Simons 1944; Grout 1984). In general equilibrium, as the problem of creating and sharing quasi-rents spreads throughout the economy, the market system will adjust to help compensate the appropriated factors, providing a highly inefficient macroeconomic "solution" to the unresolved microeconomic contracting problems. This general-equilibrium adjustment can affect major aspects of the aggregate functioning of the economy.

In this paper we attempt to characterize the nature and implications of the macroeconomic "solution" to the holdup problem. ${ }^{2}$ Throughout the paper we think of the problem as one where two factors of production contemplate either committing to a partly irreversible joint-production relationship, or remaining in "autarky." Section 2 sets up this model and draws some basic macroeconomic implications. The problem of appropriability implies, in general equilibrium, that factors of production are underemployed; that the market for the "appropriating" factor is segmented (i.e., it experiences involuntary unemployment in joint production); that the productive structure is "sclerotic" (i.e., too many low-productivity units are kept in operation compared to an efficient economy); and that, paradoxically, the economy exhibits excessive destruction of production units given its depressed level of creation. The section concludes with a discussion of the canonical set of policies that restore macroeconomic efficiency.

Section 3 turns to cyclical implications, and focuses more closely on the labor/capital interpretation of the two factors - where we take those factors' distinguishing features to be that the supply of uncommitted capital to form joint-production units to be more elastic

\footnotetext{
${ }^{2} \mathrm{~A}$ number of recent contributions have examined various implications of appropriable quasi-rents in general equilibrium setting. Makowski and Ostroy (1995) highlight the key role that "appropriation" plays in the efficiency of markets. Ramey and Watson (1996) analyze the interactions of the holdup problem and effort incentivization in a matching model. More applied examples are MacLeod and Malcomson (1993), who study the macroeconomic effects of employment contract forms that attempt to avert investment holdup; Acemoglu (1996), who examines the effects of search-related incomplete contracting on human capital accumulation; and Robinson (1995), who looks at the economics and politics of labor-market institutions when employment contracts are incomplete.
} 
than that of labor. In this context, we show that, at low levels of activity, labor is the factor that experiences market segmentation (i.e., there is involuntary labor unemployment), while at high levels of activity it is the market for capital that is segmented (i.e., there are labor shortages). Moreover, the cyclical response of the economy is excessively elastic (compared to an efficient economy) when the labor market is segmented, and excessively rigid when the capital market is segmented. Put differently, recessions bring unnecessarily severe unemployment, while expansions run into bottlenecks sooner than efficient. This implies, in particular, that the economy will have an asymmetric response to a symmetric shock process - with sharp recessionary dips and recoveries followed by shallow expansions. Moreover, this asymmetry implies that an increase in the volatility of macroeconomic shocks will decrease average employment and output. We conclude that while - depending on the nature of the shock - expansions may require stabilization or reinforcement, recessions should always be softened.

Section 4 touches on issues relating to the longer-term response of institutions and technology to the presence of unprotected specificity. From a political point of view, each factor will seek, as an ex ante united group, institutional developments that increase the other factors' specificity. But this political incentive for rent appropriation has its limits, because it inherently results in ex post internal segmentation of the appropriating factor between employed winners and unemployed losers. It is through that channel that the macroeconomic inefficiency of opportunism enters into the factor's political calculation, and, beyond a point, starts dominating any additional distributional gain.

Over the long run, the economy will also respond along its technological dimension in an attempt to circumvent the appropriability problem. A principal dimension of technological adaptation is in the relative factor proportions used. We show how, in equilibrium, technology choice is essentially determined by the appropriated factor. That factor, we argue, has an incentive to reduce appropriation by selecting a technology that partly "excludes" the other factor from joint production. The result is a distorted capital-labor ratio and further under-employment of the appropriating factor. This exclusion phenomenon is consistent with the role that capital-labor substitution seems to have played in the rise of European unemployment.

Section 5 concludes with a series of macroeconomic questions that can be illuminated by drawing on the ideas developed in this paper. An appendix follows. 


\section{Appropriable Rents in General Equilibrium}

\subsection{Factor Specificity in Joint Production}

In this section we lay out the model that we use to analyze the general-equilibrium implications of specific quasi-rents in the joint use of factors of production. Our basic model takes as given the institutional framework and available technology. It is therefore appropriate for the study of short to medium term equilibrium, but must be used more selectively in the study of long-term issues. Section 4 discusses the implications of endogenizing long-run institutional and technological evolution.

Productive structure

Our model economy has one consumption good and two factors of production, denoted as factor 1 and 2. The two factors are identified with optimizing agents, who derive linear utility from the consumption good, which we use as the numeraire.

Production takes place in two modes, identified with separate sectors of the economy. Factors 1 and 2 can either produce separately in their respective Autarky sectors, or combine in the Joint Production sector. For each factor $i$, we denote by $U_{i}$ total employment in Autarky and by $E_{i}$ total employment in Joint Production.

Each factor's Autarky sector is perfectly competitive and characterized by an aggregate production function $F_{i}\left(U_{i}\right)$. In Joint Production, factors 1 and 2 combine in fixed proportions to form "production units." A production unit combines $x_{1}$ units of factor 1 with $x_{2}$ units of factor 2 to produce $\widetilde{y}$ units of the consumption good. We denote by $E$ the total number of production units. Parameters $x_{1}, x_{2}>0$ and $\widetilde{y}$ are given by available technologies. The implications of allowing for short-run substitutability between factors, and for even greater substitutability in the long run through technological development will be discussed in section 4 .

\section{Creation and destruction}

We study a one-period economy. There is a mass $E^{o}$ of pre-existing production units that were formed before the start of the period. There is also a mass $U_{1}^{o}$ and $U_{2}^{o}$ of uncommitted factors of type 1 and 2, that are not part of a pre-existing unit. For each factor $i=1,2$, we fix total factor supply to one:

$$
x_{i} E^{o}+U_{i}^{o}=1
$$

Production units that are newly created this period have common revenue $y^{n}$. Pre-existing production units have heterogeneous revenues $\widetilde{y}^{o}$, whose distribution $D\left(\widetilde{y}^{o}\right)$ is given by the 
history of technology adoption and idiosyncratic shocks. Naturally, $D(+\infty)=E^{o}$. If the minimum revenue required for survival (see below) is denoted by $\underline{y}^{\circ}$, then the total number of pre-existing units destroyed is $D\left(\underline{y}^{o}\right)$.

The timing of production is as follows. In a first phase, pre-existing production units decide whether to continue operation for this period, or to separate and release their factor resources. In a second phase, factors that were released from pre-existing units and uncommitted factors can choose to form new production units, or remain in Autarky. In the final phase, factors in all sectors produce.

A number of identities will be useful in what follows. Denoting by $C$ the number of new units created, and recalling that $D\left(\underline{y}^{\circ}\right)$ is the number of pre-existing units destroyed, we have

$$
\begin{gathered}
E=E^{o}+C-D\left(\underline{y}^{o}\right) \\
E_{i}=x_{i} E \\
U_{i}=U_{i}^{o}-x_{i} C+x_{i} D\left(\underline{y}^{o}\right),
\end{gathered}
$$

where $i=1,2$. The first identity equates the number $E$ of production units to the number of pre-existing units plus net creation; the second gives Joint Production employment for each factor as a function of $E$; the last identity gives Autarky employment for each factor as a function of the number of uncommitted factors and net creation.

\section{Specificity and incomplete contracts}

When factors join to form a new production unit, they develop a degree of specificity with respect to each other, and a share $\phi_{i} \in[0,1]$ of factors $i=1,2$ can no longer be used outside the production unit. If the factors separate, only $\left(1-\phi_{i}\right) x_{i}$ units of factor $i$ can be used elsewhere. Specificity can be a pure aspect of technology, or, as discussed in the examples of section 2.2 , can be due to institutional factors.

Specificity creates quasi-rents whose value is the difference between the value of the factors within the production unit and their value in their best outside use. To guarantee that specific quasi-rents will be divided according to the factors' ex-ante terms of trade, the factors must enter an ex-ante contract that governs their participation in the production unit and the division of its surplus. Unfortunately, such ideal contracts are quite difficult to achieve in practice.

In general, the contract must take into account the full complexity of the concrete situation. Specific investments are typically made not once, but incrementally throughout the 
life of a production unit. The contingent plan for making such investments, the duration of the relationship, and the rent-division mechanism must be pre-specified from the start and made fully contingent on the future profitability of the production unit, on factors that determine its evolving prospects, and on the various events, both aggregate and idiosyncratic, that govern each factor's outside opportunity costs. The contract must also specify the many dimensions that characterize each factor's participation in production, again possibly based on contingencies outside the factors' control. A variety of problems of observability, verifiability, enforceability, and sheer complexity, make such ideal contracts rarely possible. In practice, agents enter into arrangements - what one might loosely call "incomplete contracts" - that leave plenty of room for ex-post discretion. ${ }^{3}$ (For a clear discussion of incomplete contracts in the presence of specificity, see chapter 4 of Hart 1995).

When pre-contracting is not possible, the division of specific quasi-rents must be determined ex post. It is well known that, in this case, the relation between the two factors undergoes, in Williamson's (1985) term, a "fundamental transformation" from an ex-ante competitive setting to an ex-post bilateral monopoly. To analyze the effect of incomplete contracting, we distinguish between two extreme cases: the "efficient" equilibrium, where factors are able to engage in full contractual precommitment, and the "incomplete contracts" equilibrium, where no precommitment is possible.

Free entry and exit

We can now turn to the determination of factor rewards in different sectors, and the freeentry and exit decision rules for production units. If we denote by $p_{i}$ factor $i$ 's rental price in Autarky, we have

$$
p_{i}=F_{i}^{\prime}\left(U_{i}\right)
$$

in any equilibrium with $0<U_{i}<1$. Assuming the functional form

$$
F_{i}\left(U_{i}\right)=\frac{1}{1+1 / \eta_{i}}\left[1-\left(1-U_{i}\right)^{1+1 / \eta_{i}}\right], \quad \eta_{i}>0
$$

for the Autarky production function, we get a constant supply-elasticity $\eta_{i}$ for factor $i$ into

\footnotetext{
${ }^{3} \mathrm{~A}$ simple transaction that would overstep the need for contracting altogether is an exchange of factors that allows a single agent to own both factors in a production unit. In the first two examples we develop in section 2.2 below, this solution is made impossible by the fact that one side of the transaction involves "inalienable" human capital. In the third example, it is limited by span-of-control and other limits to the extent of vertical integration.
} 
Joint Production:

$$
E_{i}=p_{i}^{\eta_{i}}, \quad i=1,2,
$$

taking (1) and (2)-(4) into account. Naturally, $F_{i}\left(U_{i}\right)$ is increasing and concave in $U_{i}{ }^{4}$

Turning to Joint Production, we let $w_{i}^{n}$ denote the unit-compensation of factor $i$ in a newly created production unit. To differentiate between variables when equilibrium conditions are different for the efficient and incomplete-contracts equilibrium, we use an asterisk to denote the former. In the efficient equilibrium, factors in new production units are compensated according to their ex-ante opportunity cost $p_{i}^{*}$, i.e.

$$
w_{i}^{n *}=p_{i}^{*}, \quad i=1,2 .
$$

In the incomplete-contracts equilibrium, factor compensation in new production units is governed by their ex-post opportunity $\operatorname{cost}\left(1-\phi_{i}\right) p_{i}$. The specific quasi-rent $s^{n}$ from such a production unit is the difference between the unit's revenue $y^{n}$ and the ex-post opportunity costs of its factors:

$$
s^{n}=y^{n}-\left(1-\phi_{1}\right) p_{1} x_{1}-\left(1-\phi_{2}\right) p_{2} x_{2} .
$$

Following the Nash bargaining solution for sharing the unit's revenue, we assume that each factor $i$ gets its ex-post opportunity cost plus half of the unit's bargaining surplus $s^{n}: 5,6$

$$
w_{i}^{n} x_{i}=\left(1-\phi_{i}\right) p_{i} x_{i}+\frac{1}{2} s^{n}
$$

In the efficient case, the entry condition for the creation of new units is

$$
y^{n} \geq p_{1}^{*} x_{1}+p_{2}^{*} x_{2}
$$

\footnotetext{
${ }^{4}$ The strict concavity of the Autarky production function implies the presence of a third "quasi" factor. This becomes relevant in the distributional analysis of section 4.1, where it is briefly discussed (see footnote 20).

${ }^{5}$ We implicitly assume that each type of factor in the production unit forms a coalition that bargains as a single agent.

${ }^{6}$ An alternative specification of the "disagreement point" in bargaining yields the Shaked and Sutton (1984) sharing rule that allocates $\frac{1}{2} y^{n}$ to each factor as long as neither factor $i=1,2$ receives less than $\left(1-\phi_{i}\right) p_{i} x_{i}$. (See Binmore, Rubinstein, and Wolinsky 1986 for a discussion of the foundational differences between the two approaches). The discrete change in the way the opportunity cost $\left(1-\phi_{i}\right) p_{i} x_{i}$ enters the Shaked-Sutton rule makes it less attractive for an "aggregate" model. Otherwise, our main conclusions do not depend on the specific sharing rule.
} 
In the incomplete-contracts case, the rule for factor $i$ to participate in Joint Production is

$$
w_{i}^{n} \geq p_{i}, \quad i=1,2 \text {. }
$$

It is easy to show from (8)-(9) that (11) is equivalent to

$$
y^{n} \geq p_{i} x_{i}+p_{\neg i} x_{\neg i}+\left(\phi_{i} p_{i} x_{i}-\phi_{\neg i} p_{\neg i} x_{\neg i}\right), \quad i=1,2
$$

where $\neg i$ denotes the factor other than $i$. The difference between the efficient entry condition (10) and this condition for factor $i$ is the term

$$
\Delta_{i} \equiv \phi_{i} p_{i} x_{i}-\phi_{\neg i} p_{\neg i} x_{\neg i}
$$

Considering that the expression $\phi_{j} p_{j} x_{j}$ measures the value of what factor $j$ sinks into the relationship, $\Delta_{i}$ measures the net effective specificity of factor $i . \Delta_{i}$ is positive if $i$ sinks in a greater value than the other factor, and negative otherwise. Since $\Delta_{\neg i}=-\Delta_{i}$, we denote their absolute value by $\Delta \equiv\left|\Delta_{i}\right|$. Condition (12) for $i$ requires that revenues $y^{n}$ cover the two factors' outside opportunity costs, plus the net effective specificity $\Delta_{i}$ factor $i$ would sink into the relationship. It is obvious that it is the entry condition of the factor with positive net specificity that is binding, so that, taken together for $i=1,2$, the two entry conditions (12) are equivalent to

$$
y^{n} \geq p_{1} x_{1}+p_{2} x_{2}+\Delta
$$

We now turn to the separation decision of factors in pre-existing units. To avoid clouding the analysis with side-effects, we do not assume that pre-existing units exhibit any factor specificity. Otherwise, because factors would lose a fraction $\phi_{i}$ if the unit separates, total factor supply would effectively depend endogenously on destruction, and would therefore not be fixed. Measuring the probability that a unit of factor $i$ will be employed in Joint Production by

$$
\lambda_{i} \equiv \frac{x_{i} C}{U_{i}^{o}+x_{i} D\left(\underline{y}^{o}\right)},
$$

the opportunity cost of factors in a pre-existing unit is $\lambda_{i} w_{i}^{n}+\left(1-\lambda_{i}\right) p_{i}$. For a pre-existing unit to survive, its revenues must at least cover the sum of its two factors' opportunity 
costs. ${ }^{7}$ In other words, the free-exit condition for a pre-existing unit is $\widetilde{y}^{o} \geq \underline{y}^{o}$, where the "destruction margin" $\underline{y}^{o}$ is given by

$$
\underline{y}^{o}=\lambda_{1} w_{1}^{n} x_{1}+\left(1-\lambda_{1}\right) p_{1} x_{1}+\lambda_{2} w_{2}^{n} x_{2}+\left(1-\lambda_{2}\right) p_{2} x_{2}
$$

By equation (7), in the efficient equilibrium, the revenue requirement for survival reduces to

$$
\underline{y}^{o *} \equiv p_{1}^{*} x_{1}+p_{2}^{*} x_{2}
$$

Efficient and incomplete-contracts equilibrium

We are now ready to define equilibrium in both the efficient and the incomplete-contracts case. We make parameter assumptions that guarantee an "interior" equilibrium in both cases, so that free-entry condition (14) holds with equality and all sectors have positive employment.

Assumption 1 (Interior Equilibrium) We assume that $0<y^{n}<z_{y}$ and $E^{o}<z_{E}\left(y^{n}\right)$, where $z_{y}$ is given by

$$
z_{y}=\min \left\{x_{1}\left(1+\left(\frac{x_{2}}{x_{1}}\right)^{1+1 / \eta_{2}}\right), x_{2}\left(1+\left(\frac{x_{1}}{x_{2}}\right)^{1+1 / \eta_{1}}\right)\right\}
$$

and $z_{E}\left(y^{n}\right)$ is defined implicitly by

$$
y^{n}=x_{1}^{1+1 / \eta_{1}} z_{E}^{1 / \eta_{1}}+x_{2}^{1+1 / \eta_{2}} z_{E}^{1 / \eta_{2}}+\max \left\{x_{1}^{1+1 / \eta_{1}} z_{E}^{1 / \eta_{1}}, x_{2}^{1+1 / \eta_{2}} z_{E}^{1 / \eta_{2}}\right\}
$$

The upper-bound $z_{y}$ on $y^{n}$ guarantees that Joint Production revenues are not high enough to drive Autarky employment to zero. The upper-bound $z_{E}$ on the number $E^{o}$ of preexisting units guarantees a need for positive creation. ${ }^{8}$

An (interior) incomplete-contracts equilibrium is a set of variables $\left(C, E, E_{1}, E_{2}, p_{1}, p_{2}\right.$, $\left.w_{1}^{n}, w_{2}^{n}, \underline{y}^{o}\right)$ that satisfies free-entry condition (14) with equality, as well as equations (2)(3), (6), (8)-(9), (13), and (15)-(16). An (interior) efficient equilibrium is a set of variables $\left(C^{*}, E^{*}, E_{1}^{*}, E_{2}^{*}, p_{1}^{*}, p_{2}^{*}, w_{1}^{n *}, w_{2}^{n *}, \underline{y}^{o *}\right)$ that satisfies the efficient free-entry condition (10)

\footnotetext{
${ }^{7}$ This separation rule is privately efficient. Specific quasi-rents give rise to the possibility of privately inefficient separations whenever there is a "non-transferability" problem, due, for example, to asymmetric information. See Myerson and Satterthwaite (1983) for a general result, and Hall and Lazear (1984) for an application to the labor market.

${ }^{8}$ This condition is stronger than needed at this stage, but it will turn out to be helpful in the rest of the paper.
} 
with equality, as well as equations (2)-(3), (6)-(7), and (17) with $\left(C, E, E_{1}, E_{2}, p_{1}, p_{2}, \underline{y}^{o}\right)$ replaced by $\left(C^{*}, E^{*}, E_{1}^{*}, E_{2}^{*}, p_{1}^{*}, p_{2}^{*}, \underline{y}^{o *}\right)$. The following proposition establishes existence and uniqueness for both types of equilibrium (proofs for all propositions can be found in the appendix).

Proposition 1 (Existence and Uniqueness) An incomplete-contracts equilibrium exists, is unique, and satisfies $C, E_{i}, U_{i}>0, i=1,2$. An efficient equilibrium exists, is unique, and satisfies $C^{*}, E_{i}^{*}, U_{i}^{*}>0, i=1,2$.

Assumption 1 guarantees that equilibrium is characterized by positive creation and positive employment in Joint Production and Autarky.

Before we turn to the basic implications of our model, it is useful to look at some examples.

\subsection{Examples}

Specificity and appropriable quasi-rents characterize a variety of transactions that are prevalent throughout the economy. Our highly stylized model can be given a number of interpretations. We discuss three main examples that touch on the labor, financial, and goods markets.

\section{Example 1: Labor and capital}

The two factors can be interpreted as labor and capital (now denoted as $i=l, k$ ). This is the prime example in this paper, and will be used specifically to develop the analysis in sections 3 and 4. Joint Production consists of worker employment and capital investment within the firm. Autarky for workers corresponds to "unemployment" - voluntary or involuntary or employment in sectors that are relatively immune to contracting problems (and example typical of the developing world is the "informal" sector, where constant returns and low capital requirements allow for self-employment). Autarky for capital corresponds either to investment abroad, or consumption. We think of labor as the relatively inelastic factor (low $\eta_{l}$ ), while capital is relatively elastic (high $\eta_{k}$ ).

Firm and worker typically sink various forms of specific investments into their relationship (see Becker 1964, for example). $\phi_{k}>0$ arises when the firm finances organizational or human capital embodied in the worker. Why does not the worker make the investment instead? Possibly because the investment is firm-specific as well as worker-specific, and possibly because the worker does not have sufficient wealth (and cannot obtain competitive 
outside financing for the same incomplete-contracts reasons that render the firm's investment appropriable). $\phi_{l}>0$ arises when the worker dedicates part of his lifetime learning opportunities to firm-specific knowledge. A special case of firm- and worker-specificity that has been studied extensively in the labor-market literature are search costs expended by firms and workers, which, by their very nature, cannot be protected by ex-ante contracting. Generally, one expects each side to make, over time and in various ways, investments that are specific to the other, so that both $\phi_{l}$ and $\phi_{k}$ will be positive.

Specificity can have an important institutional origin, in addition to its technological dimension. Consider, for example, the case of workers who are able to form a union to negotiate with their employer. The power of the union may derive from firm investments that are embodied in workers as a group - again, ultimately a contracting problem - or from legislation. ${ }^{9}$ With unions, it is not only worker-specific investments but the full set of firm- or industry-specific capital that can become relationship-specific and enter the scope of the union. Legislation on dismissals and severance pay provides another example of institutionally-driven specificity. The imposition of severance pay, for example, depending on the form it takes, would effectively increase $\phi_{k}$ or reduce $\phi_{l}$.

\section{Example 2: External finance}

A second interpretation is to think of the above as modelling the external financing of firms. The first factor would then represent "managers," who possess management and entrepreneurial skills; the second factor would represent the capital of outside financiers (shareholders and lenders). The delegation of control rights over the firm's assets to management makes those assets partly management-specific (e.g., Williamson 1988; Hart and Moore 1994). If it withdraws from the relationship, management can, in various ways, cause serious damage to the firm's value - by withdrawing their firm-specific human capital, withholding vital information on the firm and its assets, or undertaking highly disruptive acts of omission or commission. The different ways in which financiers can protect the value of their investment from management appropriation is the subject of the "corporate governance" approach to finance (see, e.g., Shleifer and Vishny 1995). Although we do not emphasize this interpretation, our results can help shed light on the macroeconomic implications of financial constraints (see Caballero and Hammour 1996c).

\footnotetext{
${ }^{9}$ See, e.g., Lindbeck and Snower (1986). In this context, appropriability finds its clearest expression in the phenomenon of "strikes." The only reason strikes put any pressure on employers is that it is costly for technological or legal reasons - to substitute outsiders for striking insiders, i.e. capital has some degree of specificity with respect to labor. That is precisely the leverage used by insiders to improve their deal.
} 


\section{Example 3: Vertical relationships}

A third example draws on the role of specificity in the literature on vertical integration

(e.g., Klein, Crawford, and Alchian 1978). Our two factors would then represent the capital of upstream suppliers and of downstream customers, respectively. Buyer and seller may make mutually specific investments $\left(\phi_{i}>0\right)$. An electric utility may invest in a plant that is specific to a supplier (by locating it near a coal mine, for example) or specific to a customer (by locating near an industrial complex). A special case of this example are "customer markets," where the upstream supplier is a final-goods producer and the downstream customer is a consumer (e.g., Phelps and Winter 1970).

\subsection{Under-employment and Rationing}

A microeconomic situation where one factor is open to appropriability by another, if widespread throughout the economy, results in offsetting macroeconomic adjustments to guarantee that appropriated factors obtain adequate returns in general equilibrium and satisfy their free-entry condition. This general-equilibrium response affects major aspects of the macroeconomy, which appear as symptoms of an inefficient macroeconomic "solution" to the unresolved appropriability problems. This section describes general-equilibrium implications for factor employment.

The main benchmark for an incomplete-contracts equilibrium is an efficient economy. We start by giving parameter conditions for the incomplete-contract equilibrium to be efficient.

Proposition 2 (Balanced Specificity) The incomplete-contracts equilibrium is efficient iff, in equilibrium,

$$
\phi_{1} p_{1} x_{1}=\phi_{2} p_{2} x_{2}
$$

which will happen iff the economy's parameters satisfy

$$
\frac{1}{x_{1}}\left(\frac{\phi_{2}}{\phi_{1}+\phi_{2}} \frac{y^{n}}{x_{1}}\right)^{\eta_{1}}=\frac{1}{x_{2}}\left(\frac{\phi_{1}}{\phi_{1}+\phi_{2}} \frac{y^{n}}{x_{2}}\right)^{\eta_{2}}
$$

Condition (18) for efficiency is equivalent to requiring zero net effective specificity $\Delta .{ }^{10}$ In other words, it requires that, even though factors may sink some degree of specificity with

\footnotetext{
${ }^{10}$ Throughout we assume the two factors' bargaining share parameter to be equal. If not, the efficiency condition must me modified by dividing each side of (18) by the bargaining share of the corresponding factor.
} 
respect to each other, their interdependence be "balanced."

To interpret this balanced-specificity condition, note that effective specificity $\phi_{i} p_{i} x_{i}$ is determined not only by the specific share $\phi_{i} x_{i}$, but also by the factor's Autarky reward $p_{i}=$ $E_{i}^{1 / \eta_{i}}$. A factor with unattractive outside opportunities in Autarky (low $p_{i}$ ) has relatively low effective specificity, because the relative value of what it sinks into the relationship is low. When the factors are completely symmetric - i.e. $\phi_{1}=\phi_{2}, \eta_{1}=\eta_{2}$ and $x_{1}=$ $x_{2}$ - condition (19) for balanced appropriation holds. Positive net appropriation comes from asymmetries in the parameters that determine factor specificity. If everything else is symmetric, the appropriating factor will be $(i)$ the factor with the lower specific share $\phi_{i} x_{i}$; and (ii) the factor with the lower elasticity $\eta_{i}$.

What is the effect of appropriability if the efficient parameter condition does not hold? The first effect of appropriability is to reduce the employment level in Joint Production:

Proposition 3 (Under-employment) In an inefficient incomplete-contracts equilibrium both factors are under-employed:

$$
E_{i}<E_{i}^{*}, \quad i=1,2
$$

Underemployment results from the decreased incentives of the appropriated factor to enter Joint Production, since it is that factor's entry rule that holds with equality. Equalization $p_{i}=w_{i}^{n}$ of the appropriated factor's Autarky and Joint-Production returns is achieved partly by depressing its own opportunity $\operatorname{cost} p_{i}$ and partly by reducing the appropriating factor's opportunity cost $p_{\neg i}$ (to support $w_{i}^{n}$ ), both of which involve a reduction in JointProduction employment.

The second implication of appropriability is market segmentation of the appropriating factor:

Proposition 4 (Market Segmentation) In an inefficient incomplete-contracts equilibrium, let $i$ be the "appropriated" factor - i.e. $\Delta_{i}>0$. The market for factor $i$ clears, while the market for the other factor is segmented:

$$
w_{i}^{n}=p_{i} \quad \text { and } \quad w_{\neg i}^{n}>p_{\neg i}
$$

Net appropriation involves one of the factors capturing rents, which inherently induces market segmentation for that factor. To see this, note that the market for factor $j$ clears iff $\frac{1}{2} s^{n}=\phi_{j} p_{j} x_{j}$ (see equation 9 ), i.e. its share of specific quasi-rents exactly compensates it 
for what it sinks into the relationship. Since $\frac{1}{2} s^{n}$ goes to each of the factors, both markets clear simultaneously only under balanced specificity, i.e. when equilibrium is efficient. Otherwise, let $i$ be the appropriated factor $\left(\Delta_{i}>0\right)$. Given that we have an interior equilibrium, it is obvious from (12) that it is factor $i$ 's free-entry condition that holds with equality. The other factor market is segmented, and its return differential is obtained by replacing $\frac{1}{2} s^{n}=\phi_{i} p_{i} x_{i}$ in (9) for factor $\neg i$ :

$$
\left(w_{\neg i}^{n}-p_{\neg i}\right) x_{\neg i}=\Delta_{i}
$$

Thus, taking $\Delta / x_{\neg i}$ per unit, net effective specificity measures the extent of the appropriating factor's market segmentation.

Net appropriation gives rise to the "involuntary" unemployment of the appropriating factor in Joint Production, which persists because that factor cannot precommit to a compensation lower than equilibrium $w_{\neg i}^{n}$. The number of "slots" open in Joint Production is determined by the appropriated factor's free-entry condition, and are rationed among units of the appropriating factor.

\subsection{Productive Sclerosis and Unbalanced Gross Flows}

Besides the level and structure of factor employment, appropriability affects the manner in which production units restructure in response to evolving profitability.

The following proposition states that the inefficient economy exhibits "productive sclerosis," in the sense that pre-existing units are kept in operation with lower levels of profitability than in an efficient economy.

Proposition 5 (Sclerosis) An inefficient incomplete-contracts equilibrium exhibits "productive sclerosis":

$$
\underline{y}^{o}<\underline{y}^{o *}
$$

The scrapping margin in an inefficient equilibrium is lower than in an efficient equilibrium. To see why, rearrange expression (16) for $\underline{y}^{o}$ taking the accounting identity $y^{n}=w_{1}^{n} x_{1}+$ $w_{2}^{n} x_{2}$ into account:

$$
\underline{y}^{o}=y^{n}-\left(1-\lambda_{1}\right)\left(w_{1}^{n}-p_{1}\right) x_{1}-\left(1-\lambda_{2}\right)\left(w_{2}^{n}-p_{2}\right) x_{2}
$$

Since in an efficient equilibrium there is no market segmentation $\left(w_{j}^{n *}=p_{j}^{*}, j=1,2\right)$, the efficient scrapping margin is $\underline{y}^{o *}=y^{n}$. This is intuitive, since pre-existing units can be 
costlessly replaced by new units that produce $y^{n}$. On the other hand, if $i$ is the appropriated factor in an inefficient equilibrium, the market for factor $\neg i$ will be segmented $\left(w_{i}^{n}=p_{i}\right.$ and $\left.w_{\neg i}^{n}>p_{\neg i}\right)$ and expression (22) for the scrapping margin becomes $\underline{y}^{o}=y^{n}-(1-$ $\left.\lambda_{\neg i}\right)\left(w_{\neg i}^{n}-p_{\neg i}\right) x_{\neg i}<y^{n}$ (since $\lambda_{\neg i}<1$ in an interior equilibrium). In this case, the outside opportunity cost of the factors in a pre-existing unit is less than $y^{n}$ because released units of factor $\neg i$ are not guaranteed a slot in Joint Production and, with probability $1-\lambda_{\neg i}$, may end up in Autarky earning less. Sclerosis is thus tightly related to factor-market segmentation. Coupled with under-employment, it is likely to constitute a powerful drag on economic growth.

The next proposition characterizes the efficiency of the gross flows of production units. We define aggregate income as

$$
W\left(C, \underline{y}^{o}\right) \equiv y^{n} C+\int_{\underline{y}^{o}}^{\infty} \tilde{y}^{o} d D\left(\widetilde{y}^{o}\right)+\sum_{i=1,2} F_{i}\left(U_{i}^{o}-x_{i} C+x_{i} D\left(\underline{y}^{o}\right)\right) .
$$

where the argument in function $F_{i}\left(U_{i}\right)$ is obtained by replacing (4) for $U_{i}$. The proposition states that, in an inefficient economy, creation is generally insufficient and destruction is excessive. This captures an important dimension of "employment crises" during macroeconomic adjustment episodes (see Caballero and Hammour 1996a and 1996b).

Proposition 6 (Creation and Destruction) An inefficient incomplete-contracts equilibrium exhibits insufficient creation:

$$
\frac{\partial W}{\partial C}>0
$$

and excessive destruction:

$$
\frac{\partial W}{\partial \underline{y}^{o}}<0 \quad \text { when } \quad D^{\prime}\left(\underline{y}^{o}\right)>0
$$

Insufficient creation is due to the fact that the appropriated factor $i$ has reduced incentives to enter Joint Production because of positive net appropriation. When there is a positive density $D^{\prime}\left(\underline{y}^{o}\right)>0$ of pre-existing units at the destruction margin, excessive destruction is due to the excessively high compensation of the appropriating factor $\neg i$ in Joint Production, given that it is involuntarily unemployed. From a social point of view, the outside opportunity cost of a unit of factor $\neg i$ in a pre-existing unit is its Autarky reward $p_{\neg i}$; from a private point of view, it is higher and equal to $p_{\neg i}+\lambda_{\neg i}\left(w_{\neg i}-p_{\neg i}\right)$, which values 
the possibility of capturing specific rents in a new unit. This high private compensation is what causes destruction to be excessive. An extreme case arises when Autarky corresponds to unproductive labor unemployment $\left(p_{\neg i}=0\right)$. The social opportunity cost of labor in that case is zero, and any positive wage is too high and results in excessive destruction.

It may appear paradoxical that the economy exhibits both sclerosis and excessive destruction. In fact, the former is a comparison with the efficient equilibrium; and the latter is a comparison between the social and private values of a pre-existing unit in the inefficient equilibrium. The coexistence of "sclerosis" and "excessive destruction" uncovers the fallacy of a "liquidationist" approach in our context, that would see in a recession a healthy way of cleansing the productive structure from sclerosis (see, e.g., De Long 1990). There is no sense in liquidating sclerotic production units if the released factors will not be reabsorbed in Joint Production through an adequate creation rate.

\subsection{Dual Optimal Policy Design}

We now turn to the problem of designing a canonical set of optimal macroeconomic policies to address the macroeconomic ills of appropriability. Those policies are not designed to address other inefficiencies due to appropriability that arise at the microeconomic level.

We define two types of canonical policies: creation incentives $\sigma^{n}$, which are subsidies added to the revenue of each new production unit; and protection subsidies $\sigma^{\circ}$, added to the revenues of each pre-existing unit. Equilibrium in this case is determined as before, by replacing $y^{n}$ in entry condition (14) by $y^{n}+\sigma^{n}$, and $\underline{y}^{o}$ in exit condition (16) by $\underline{y}^{o}+\sigma^{o}$.

Proposition 7 (Dual Optimal Policy) Efficiency can be restored in an incomplete-contracts equilibrium with the following combination of a creation incentive and a protection subsidy:

$$
\sigma^{n *}=\Delta^{*} \quad \text { and } \quad \sigma^{o *}=\lambda_{\neg i}^{*} \Delta^{*}
$$

where $\neg$ i denotes the appropriating factor (i.e. $\Delta_{\neg i}<0$ ).

The reason we need a dual policy approach even though there is only one ill - namely quasi-rent appropriation - is that this ill affects different types of agents differently. There are two types of marginal decisions in this economy: creation and destruction. The incentives for creation are depressed by $\Delta$, which must therefore be compensated for. At the destruction margin for pre-existing units, the prospect of rent appropriation also distorts the opportunity cost of the appropriating factor. But this distortion is only equal to the 
rents $\Delta$ times the probability $\lambda_{i}^{*}$ that they will be captured. That distortion would be even lower if the factor had to scrap some specific component upon separation. In any case, the protection subsidy $\sigma^{o *}$ must therefore be lower than $\sigma^{n *}$.

What the need for two policy tools implies in practice is that, alone, a policy designed to mend things on one margin will exacerbate things on the other. A creation incentive, by itself, would exacerbate excessive destruction by increasing rents as well as the probability of capturing those rents. A protection subsidy, by itself, would reduce destruction but make the private factor costs of creation even higher. Only a combination of the two can restore efficiency. ${ }^{11}$

An application of this approach to the problem of managing macroeconomic adjustment can be found in Caballero and Hammour (1996b). In that paper, we argue that adjustment must be managed through a combination of creation incentives and protection measures for the existing structure. A purely gradualist approach, which can be thought of as a single policy-instrument approach to slowing down creation, is deficient in that it does not address - and actually exacerbates - the need to accelerate creation.

\section{Business Cycles: Slack and Bottlenecks}

In this section we analyze the effect of unprotected specificity on the economy's response to aggregate shocks. Although our simple setup does not allow a full dynamic analysis, it yields important insights into the economy's cyclical features. ${ }^{12}$ We consider the effect of an exogenous shock to gross revenues $y^{n}$, which may either affect the economy's "fundamentals" or may be due to a distortion of the "aggregate demand" or "aggregate supply" type (e.g., a tax on gross output). ${ }^{13}$ We focus more closely on the capital/labor interpretation of our two factors. For our purposes, the main distinguishing feature between capital and labor is that the supply of (uncommitted) capital is relatively more elastic than labor.

Assumption 2 (Capital/Labor) The two factors are capital (k) and labor (l). We

\footnotetext{
${ }^{11}$ There are many ways to implement the above "canonical" policies, taking into consideration the economy's regulatory and institutional context in which they operate. For example, if new and pre-existing units cannot be segregated by policy, the above can be replaced by a production subsidy $\sigma^{p}$ and a creation subsidy $\sigma^{c}: \sigma^{p *}=\sigma^{o *}$ and $\sigma^{c *}=\sigma^{n *}-\sigma^{p *}$.

${ }^{12} \mathrm{~A}$ dimension that our setup is ill designed for is the analysis of gross employment flows over the cycle, which requires a full inter-temporal analysis. We examine this question in Caballero and Hammour (1994, 1996a).

${ }^{13}$ The shock may or may not affect the revenues $\widetilde{y}^{\circ}$ of pre-existing units. This would be relevant for an analysis of gross flows over the cycle, which our setup is not designed to address.
} 
assume that uncommitted capital is more elastic than labor, and that both capital and labor exhibit some specificity:

$$
\begin{gathered}
\eta_{k}>\eta_{l} \\
\phi_{k}>0 \text { and } \phi_{l}>0 .
\end{gathered}
$$

\section{Unemployment and shortages}

How do factor employment patterns evolve over the cycle? First, it is easy to show that, as expected, higher levels of revenue are associated with higher levels of Joint-Production employment:

$$
\frac{d E}{d y^{n}}>0
$$

More interestingly, the following proposition states that, as revenue and employment rise, the economy turns from a situation where the labor market is segmented and JointProduction investment is the limiting factor for expansion to a situation where capital is segmented and labor shortages are the limiting factor.

Proposition 8 (Unemployment and Shortages) There exists a level $y^{\text {nb }}$ of revenues $y^{n}$ that satisfies balanced-specificity condition (19). In an incomplete-contracts equilibrium, if $y^{n}<y^{n b}$ the latur market is segmented; if $y^{n}>y^{n b}$ the capital market is segmented.

$y^{n b}$ corresponds to the level of revenues implicitly defined in proposition 2, at which there is zero net appropriation and the incomplete-contracts economy is efficient. At levels of activity below $y^{n b}$ capital is appropriated, while at levels higher than $y^{n b}$ labor is appropriated. As the economy expands and crosses the level of activity $y^{n b}$, it turns from a situation of involuntary labor unemployment and capital shortages for job-creation, to one of labor-market shortages and segmentation in capital markets.

How should one interpret the possibility of segmented capital markets? It is a situation where capital could obtain a higher return if invested in Joint Production but is unable to find the requisite labor. ${ }^{14}$ In terms of the stock-market valuation of Joint-Production units, Tobin's $q$ is 1 when $y^{n}<y^{n b}$ and greater than 1 when $y^{n}>y^{n b}$ (even though there

\footnotetext{
${ }^{14}$ One expects contracting problems to be less severe when labor is appropriated than when capital is. The reason is that labor is "inalienable," while capital is not. Thus, when labor is appropriated, some capital may be transferred to the worker to convince him to commit to a production unit; when capital is appropriated, the reverse transfer of labor to capital is infeasible. Although, in practice, this may not constitute a perfect solution because of asymmetric information and other reasons, it gives reason to believe that capital-market segmentation is more likely to be alleviated at the microeconomic level than labor-market segmentation.
} 
are no explicit adjustment costs). Periods of labor-market shortages are times of expensive stock-market valuations.

Although the level of revenues $y^{n b}$ seems arbitrary, we argue in section 4 that, in the long run, institutional and technological evolution are likely to result in a situation where $y^{n b}$ is within the range of revenues in which the economy fluctuates. Institutions are likely to respond to correct any imbalance in appropriation that cause macroeconomic inefficiency to rise beyond a certain point; and technologies will also be developed that allow efficient production with new factor proportions that reduce this imbalance. On both counts, one does not expect $y^{n b}$ to be far removed in the long run from the economy's average level of output.

The next proposition characterizes the economy's cyclical responsiveness at different levels of activity.

Proposition 9 (Elastification/Rigidification) The economy's cyclical response is "elastified" when the labor market is segmented, and "rigidified" when the capital market is segmented:

$$
\frac{d E / E}{d y^{n} / y^{n}}\left\{\begin{array}{llc}
>\frac{d E^{*} / E^{*}}{d y^{n} / y^{n}}, & \text { if } & y^{n}<y^{n b} \\
<\frac{d E^{*} / E^{*}}{d y^{n} / y^{n}}, & \text { if } & y^{n}>y^{n b}
\end{array}\right.
$$

When labor suffers from involuntary unemployment, the incomplete-contracts economy is more responsive to shocks than an efficient economy; when labor is the short factor, the economy's cyclical response is more rigid than in the efficient case. Thus, appropriability exacerbates recessions and brings about unnecessarily severe and involuntary unemployment, while it constrains expansions by creating labor shortages that prevent sufficient investment in new jobs. The balanced-specificity level of employment $E^{b}$ associated with $y^{n b}$ is analogous to the concept of a "natural rate." It is the level of employment at which the labor market functions effectively within the economy - it neither builds up the excessive slack of involuntary unemployment nor constitutes a bottleneck for the rest of the economy.

An intuition for why proposition 9 holds can be drawn from the under-employment result (proposition 3). As illustrated in figure 1, we know that when $y^{n}=y^{n b}$ employment in the incomplete-contracts economy is equal to that in the efficient economy, while for $y^{n} \neq y^{n b}$ employment is lower than efficient on both sides of $y^{n b} .^{15}$ Thus as revenues expand and

\footnotetext{
${ }^{15}$ Figure 1 was generated with the following parameter values: $x_{k}=0.7, x_{l}=1.4 ; \eta_{k}=8.0, \eta_{l}=0.3$;
} 


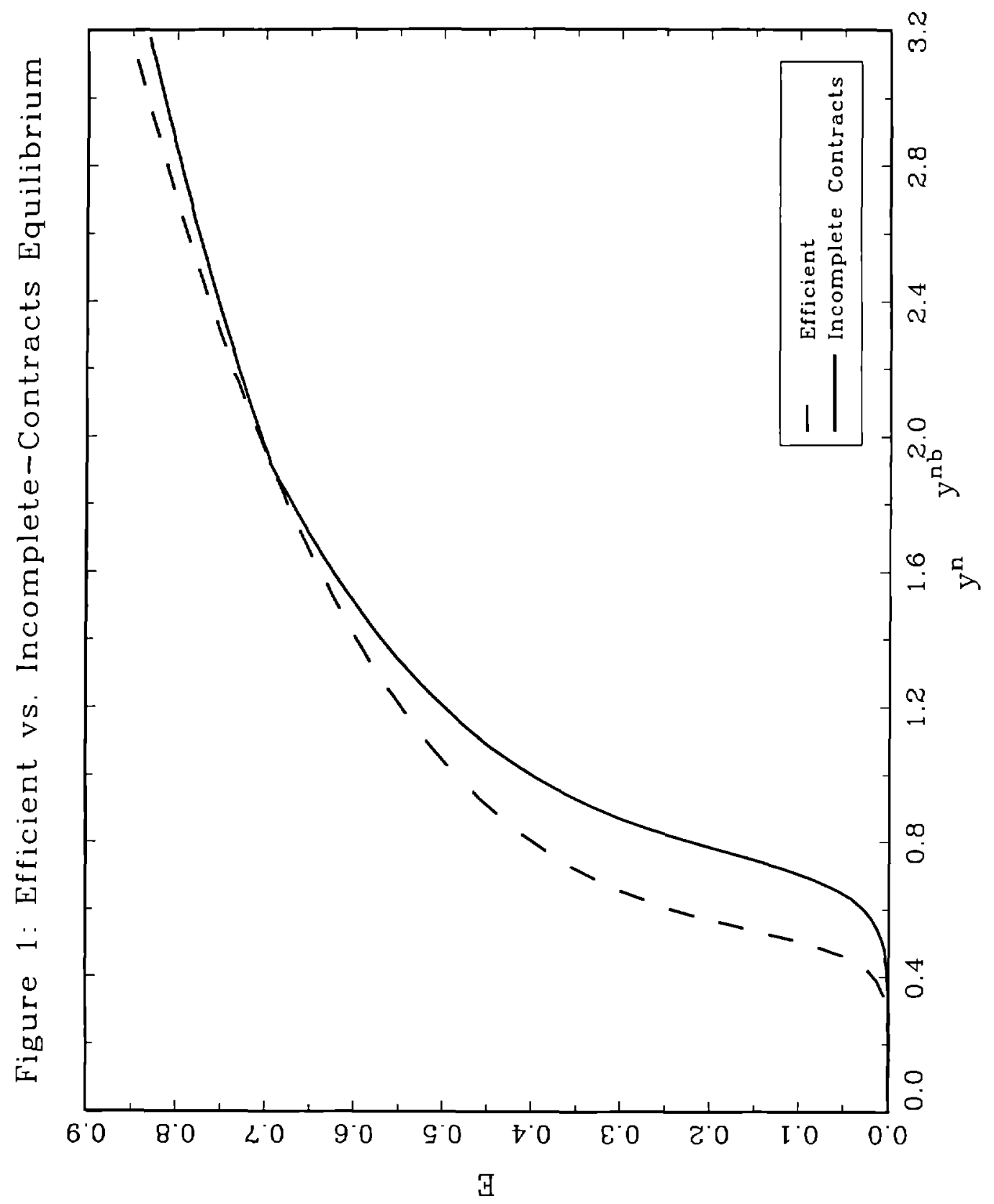


cross $y^{n b}$, employment first expands faster than in the efficient economy (to catch up with it) to the left of $y^{n b}$, then expands slower (to fall short again) to the right of $y^{n b}$. On both sides under-employment is due to one of the factors constraining employment of the other. At low revenue levels it is capital - the more elastic of the two factors - whose binding free-entry condition constrains labor employment, and induces excessive elasticity in the economy's response; while at high revenue levels, it is labor - the less elastic factor - that constrains growth and induces a rigid response.

Two interesting implications follow from proposition 9. The first is a simple application of Jensen's inequality. Because of the asymmetry in the economy's cyclical responsiveness at low and high levels of activity, an increase in the volatility of aggregate shocks around $y^{n b}$ inefficiently lowers average Joint-Production employment and output. This "level" effect can lead to high costs of macroeconomic instability.

Second, the economy will exhibit an asymmetric cyclical response to a symmetric shock process. Figure 2 gives a stylized representation of the model's implications for symmetric cycle in revenues around $y^{n b}{ }^{16}$ The two curves represent the sequence of (static) equilibrium employment levels that correspond to each revenue level over the cycle, with the curves' averages shown as a straight line. The dashed curve represents the response of an efficient economy, which is symmetric around the average employment level $E^{b}$. The solid curve represents the response of the incomplete-contracts economy. It is asymmetric, with excessive elasticity at low activity levels and excessive rigidity at high activity levels, and exhibits lower average log-employment than the efficient economy. The resulting cyclical pattern is reminiscent of asymmetries documented for the US business cycle, such as the apparent asymmetry in the economy's response to negative and positive oil-price shocks. Sichel (1992), for example, characterizes post-war fluctuations in US output as consisting of three phases: contractions, high-growth recoveries to pre-recession levels, and moderategrowth periods. The corresponding pattern in figure 2 are the relatively sharp and short recession-recovery phases below average $E$, and the shallow and more prolonged phase of moderate expansion above it.

\section{Stabilization policy}

There is a strong case for trimming recessions in the presence of appropriability, irrespective of whether the adverse shock affects fundamentals or is due to an aggregate distortion -

$\phi_{k}=0.4, \phi_{l}=0.2$.

${ }^{16}$ Figure 2 was generated with the same parameter values as figure 1. 


$$
8
$$


i.e., whether it affects the "central planner" problem or not. When a shock to fundamentals brings employment below $E^{b}$, proposition 7 indicates that the optimal response to labor unemployment and sclerosis is to apply creation and employment incentives. This is all the more necessary in the presence of a distortionary shock, since an efficient economy should not contract at all in that case.

The appropriate policy response during expansions is more ambiguous. If the shock is distortionary, it should be stabilized. However, if the favorable shock is to fundamentals and takes the economy beyond $E^{n b}$, proposition 7 again prescribes a combination of expansionary incentives that reduce the economy's bottlenecks and allow it to expand beyond its "natural" rate. Thus, while recessions are always inefficiently severe, expansions may well be "golden opportunities" that call for reinforcement rather than stabilization. In this sense, recessions should be systematically trimmed, while much greater care should be taken not to curtail real opportunities for expansion. ${ }^{17}$

\section{Institutional and Technological Evolution}

In the short term, factors' net specificity $\Delta_{i}$ varies mostly as a result of the generalequilibrium response of Autarky prices to changes in macroeconomic conditions. Over the medium and long term, however, institutional and technological forces are likely to directly affect net specificity through changes in unitary specificity (the $\phi_{i}{ }^{\prime}$ 's) and through factor substitution $\left(x_{k} / x_{l}\right)$. This section explores the long-run institutional and technological responses to the problem of appropriability.

\subsection{An Institutional Balancing Act}

Institutions arise as the rules that govern the transactions between agents or groups of agents. At the level of individual transactions between workers and firms, institutional arrangements often arise as ways to improve efficiency by alleviating appropriability problems and "minimizing transactions costs." Institutions also develop to regulate interactions between "coalitions" of labor and capital owners, be it at the level of corporate governance (e.g., firm-union bargaining or corporatist representation) or at the political level through the legal and regulatory environment (e.g., right-to-strike or severance-pay legislation). In

\footnotetext{
${ }^{17}$ See De Long and Summers (1988), e.g., for a related view of business cycles as "repeated transient and potentially avoidable lapses from sustainable levels of output" and of good policy as aiming to "filling troughs without shaving peaks" (p. 438).
} 
this function, institutions can play a distributional as well as an efficiency role, and embody the entrenched interests of different groups. ${ }^{18}$

This section tries to account for the labor and capital interest-group incentives to develop institutions that affect their mutual "specificity." Although interest groups may be strongly driven by distributional concerns, we argue that the institutional outcome is unlikely to drift very far from balanced specificity.

\section{The politics of capital and labor}

Institutional arrangements can reinforce the effective specificity of one factor with respect to another by allocating rights (e.g., the right not to lose one's job "without cause") or by making otherwise feasible contracts unenforceable (e.g., the unenforceability of worker commitment to long-term employment contracts). In order to capture this institutional dimension of specificity, we think of the $\phi_{i}{ }^{\prime}$ s as having an institutional component which is, to a large extent, a political choice variable. We analyze different groups' interest in changing the $\phi_{i}$ 's.

Since institutions typically take time to evolve, at this stage we think of the single period in our model as representing the long run. We view this "long run" as an attractor that pulls evolutionary forces. From this perspective, initial conditions matter less and we may assume that there are no pre-existing units: ${ }^{19}$

Assumption 3 (Long Run) There are no pre-existing units: $E^{o}=0$.

In order to get to the incentives of different interest-groups, we denote by $W_{i}$ the aggregate income of each of the factors. Under assumption 3 , it is easy to see that

$$
W_{i}=w_{i}^{n} E_{i}+p_{i}\left(1-E_{i}\right), \quad i=l, k
$$

The first term is the income of units of factor $i$ engaged in Joint Production, and the second term is the income of units in Autarky. ${ }^{20}$ The interest of factor $i$ as a whole is to

\footnotetext{
${ }^{18}$ Recent analyses of the politics of institutional development include Robinson $(1995,1996)$, who analyzes the politics of labor-market institutions; and Roe (1994), who gives a political interpretation to the origins of US corporate governance arrangements.

${ }^{19}$ Thus, we view pre-existing units as powerful enough to affect the time and speed at which institutions evolve and, perhaps, the precise limit to which institutions converge, but not powerful enough to change the basic course of long-run institutional developments.

${ }^{20} W_{l}+W_{k}$ do not add up to aggregate income $W$ as defined in (23). The difference corresponds to the income $\sum_{i=l, k} F_{i}\left(U_{i}\right)-p_{i} U_{i}$ that accrues the "shadow" factor implicit in our decreasing-returns assumption on the Autarky production functions $F_{i}\left(U_{i}\right)$. We do not consider the political incentives of this third "factor."
} 
maximize $W_{i}$, but there are distributional issues within each group in the presence of market segmentation. The argument for maximizing $W_{i}$ in the "long run" is that it represents the factor's unconditional expected income. ${ }^{21}$ We also analyze the ex post incentives of factor owners in Joint Production and Autarky.

Proposition 10 (Interest Groups) For each factor $i=l, k$, consider the problem of finding the pairs $\left(\phi_{l}, \phi_{k}\right) \in[0,1]^{2}$ that maximize the ex ante aggregate factor income $W_{i}$ arising in the corresponding incomplete-contracts equilibrium.

(i) There is a line segment that crosses the parameter space $\left(\phi_{l}, \phi_{k}\right) \in[0,1]^{2}$ and along which any point maximizes $W_{i}$. To all points on that segment there corresponds a unique measure $\Delta=\widehat{\Delta}^{[i]} \geq 0$ of net effective specificity in favor of factor $i$, and a unique level of Joint-Production employment $E=\widehat{E}^{[i]}$.

(ii) A unit of factor $i$ employed ex post in Autarky receives $p_{i}$, which is maximized for any pair $\left(\phi_{l}, \phi_{k}\right) \in[0,1]^{2}$ that yields an efficient equilibrium; while a unit of factor $i$ employed ex post in Joint Production receives $w_{i}^{n}$, which always increases with $\phi_{\neg i}$ and falls with $\phi_{i}$.

The first part of this proposition states that each factor $i$, as a whole, would choose an institutional arrangement that creates in equilibrium net specificity $\widehat{\Delta}^{[i]} \geq 0$ in its favor. The factor has an incentive to capture rents at the cost of a socially less efficient macroeconomic outcome. There is, in fact, a whole line in $\left(\phi_{l}, \phi_{k}\right)$-space that yields any desired level of net specificity (recall that $\Delta_{i} \equiv \phi_{i} p_{i} x_{i}-\phi_{\neg i} p_{\neg i} x_{\neg i}$ ). The different configurations along this line may correspond to widely different degrees of institutional "rigidity" - i.e., different abilities to accommodate in the short run changes in the macroeconomic environment. It is not difficult to conceive of situations where the historical evolution process does not lead to the most "flexible" configuration - i.e., the configuration with the lowest $\phi_{l}$ and $\phi_{k}$.

The political incentive for each factor to appropriate rents has its limits. The reason for this is stated in the second part of the proposition. Inherently, a factor's attempt to capture rents results in own-market segmentation, and creates winners and losers within the interest group. The winners are "insiders" employed in Joint Production, whose ex post incentive

\footnotetext{
${ }^{21}$ We assume that interest groups recognize the general-equilibrium impact (on $p_{i}$ 's and $\lambda_{i}{ }^{\prime} s$ ) of their political choices. Although "partial-equilibrium myopia" can undoubtedly play an important role in the political process, our assumption captures the idea that interest groups will partly anticipate and partly adjust to the general-equilibrium consequences of their choices.
} 
from rent appropriation is unlimited; the losers are "outsiders" who remain in Autarky, and whose ex post incentive is to minimize macroeconomic inefficiency. It is therefore through the internal segmentation of the appropriating factor that macroeconomic efficiency enters its $e x$ ante objective function and limits its incentive for rent appropriation.

The degree to which institutions can deviate from balanced specificity is therefore bounded. If in the long run political power lies with ex ante interest groups, $\widehat{\Delta}^{[l]}$ and $\widehat{\Delta}^{[k]}$ represent upper bounds on capital's and labor's long-run net specificity. Beyond those limits, both factors would attempt to reduce the degree of appropriation in the economy. ${ }^{22}$ It is in this sense that we expect institutional forces to perform a "balancing act," and keep the economy from deviating too far away from balanced specificity.

\section{Institutional rigidity}

Institutions are slow to evolve and adapt, and they often react to crises rather than anticipate them. Even though large and persistent changes in the macroeconomic environment would eventually lead to institutional adjustment, in the meantime it is proposition 8 (unemployment/shortages) that determines the fortunes of different factors of production. Suppose, for example, that the political outcome leads to a situation of balanced specificity for a certain expected level of $y^{n}$. If realized $y^{n}$ is less than expected, the labor market will be segmented; and if realized $y^{n}$ is more than expected, the capital market will be segmented.

This mismatch between the frequency at which institutions react and that at which shocks occur, together with our analysis of the incomplete-contracts economy's response to shocks, naturally fits with accounts of European macroeconomic performance in the postwar period. The European experience in the fifties and sixties was one where vigorous growth (high $y^{n}$ ) allowed the development of welfare-state institutions that benefited labor in its relationship with capital (high $\phi_{k}$ ) without much cost in terms of unemployment or resistance on the part of capital. In fact Europe exhibited signs of labor shortages during that period, which necessitated a substantial flow of immigrant labor. The seventies and eighties were a period of negative aggregate shocks, often contractionary policy, and productivity slowdown (volatile and low $y^{n}$ ). The institutions that evolved after the war became a burden on the labor market and gave rise to a serious unemployment problem (proposi-

\footnotetext{
${ }^{22}$ Becker (1983) provides another argument why a highly inefficient political outcome is unlikely to persist, in an analysis that attempts to unify the view that government favors interest groups with the view that government corrects market failures. Taking an economic approach to political behavior, he argues that pressure groups benefitting from activities that raise efficiency have an intrinsic advantage in the competition for influence over groups harmed by those activities, and therefore will lobby more effectively for efficiency.
} 
tion 8). The institutional framework has responded, but quite slowly as it faced resistance from secure "insiders." Unions, for example, are today much weaker than they used to be. Technology also seems to have adjusted with substantial capital-labor substitution, a point we come to in the next section. In the meantime, proposition 7 recommends introducing large job-creation incentives, while the requisite "protection subsidies" are probably more than provided for by existing job-protection legislation (which, unlike pure subsidies, have the unfortunate effect of effectively increasing capital specificity). ${ }^{23}$

\subsection{Technological Development: Factor Exclusion and Withdrawal}

Although fixed in the short run, technology is a major dimension along which production units can adapt to the appropriability problem. In this respect, a central aspect of technology is relative factor intensity. Even though available technologies may allow limited factor substitution in the short run, new technologies can be developed that allow a broader menu of factor intensities. In this paper, we consider an extreme form of this dichotomy, and assume fixed proportions in the short run and infinite elasticity of substitution in the long run. This section asks the question, how will technology choice respond to the appropriability problem, and how will that response in turn affect macroeconomic equilibrium? Our analysis can also be used to shed light on the consequences of allowing some factor substitution in the short run.

\section{Technological possibilities}

From a long-run perspective, we assume a technological menu characterized by a constantreturns function $y^{n}\left(x_{k}, x_{l}\right)$ that essentially relates productivity to relative factor intensity; and a function $\phi_{i}\left(x_{k}, x_{l}\right), i=k, l$, that is homogeneous of degree zero and relates unitary specificity to relative factor intensity (see below). In the short run, $x_{k}$ and $x_{l}$ are fixed, so $y^{n}$ and $\phi_{i}$ are fixed; in the long run, those variables result from technology choice and development. We assume the following functional forms.

Assumption 4 (Technological Menu) The long-run technological menu is characterized by

$$
y^{n}\left(x_{k}, x_{l}\right)=\frac{1}{2} a\left(x_{k}+x_{l}\right), \quad a>0
$$

\footnotetext{
${ }^{23}$ Some countries have opted for increased unemployment benefits, which amounts to subsidizing the segmented factor's Autarky sector and exacerbates the appropriability problem. This mechanism, it is argued, may have played an important role in the persistence of European unemployment (see, e.g., Blanchard and Jimeno 1995 and Ball 1996).
} 


$$
\phi_{i}\left(x_{k}, x_{l}\right)=\bar{\phi}_{i}\left(x_{\neg i} / x_{i}\right)^{\mu}, \quad i \in\{k, l\}, \quad \bar{\phi}_{i} \in[0,1), \mu \in[0,1] .
$$

The long-run technological menu $y^{n}\left(x_{k}, x_{l}\right)$ for production is linear, which captures maximum possibilities of long-run factor substitution. Because of constant returns the size of production units is immaterial, so an appropriate normalization allows us to identify a technology by its embodied capital/labor ratio.

Unitary specificity $\phi_{i}\left(x_{k}, x_{l}\right)$ also depends on technology and is a function of the capital/labor ratio. If a unit of capital, for example, works with more labor, it is likely to be more specialized with respect to the latter. The presumption is thus that the degree to which each unit of capital is specific to labor increases with the technology's labor intensity. The strength of this effect is captured by the parameter $\mu$. As an example, consider the possibility of substituting generic machines for specifically trained workers. Capital specificity arises if the firm finances workers' relationship-specific training. As machines are substituted for workers, the share $\phi_{k}$ of specific training in total capital investment falls. An institutional example arises when capital specificity derives from legislated severance pay. If severance pay is fixed in monetary terms, it effectively makes $\phi_{k}$ proportional to the labor/capital ratio. ${ }^{24}$

Our presentation does not aim at full generality, but focuses on selected cases that are indicative of the mechanisms likely to be at work more generally. With this in mind, we replace assumptions 1 and 2 with assumption 1 '/2':

Assumption 1'/2' (Parameter Configuration) We restrict our analysis to the following parameter configurations: (i) $a \leq 1$; (ii) $\eta_{k}=\eta_{l}=\eta>0$; and (iii) $\mu \in\{0,1\}$.

The upper-bound (i) on the productivity parameter $a$ guarantees that equilibrium with technology choice is an interior equilibrium. The elasticity-based distinction between capital and labor is not central to the results in this section, and assumption (ii) simplifies things by assuming that both factors have equal elasticity $\eta$. Assumption (iii) restricts the parameter $\mu$ in the unitary-specificity function $\phi_{i}\left(x_{k}, x_{l}\right)$ to two values, 1 or 0 . We take the first value, for which unitary specificity does depend on relative factor use, as our base case. Specifically, the functional form implies, for example, that total capital specificity $\phi_{k}\left(x_{k}, x_{l}\right) x_{k}$ is proportional to total labor use $x_{l}$ (i.e., $\phi_{k}\left(x_{k}, x_{l}\right) x_{k}=\bar{\phi}_{k} x_{l}$ ), as would indicate our training and severance-pay examples above. We contrast this with the case $\mu=0$,

\footnotetext{
${ }^{24}$ Another reason why effective specificity may depend on factor proportions is that relative bargaining strength may not be independent of the capital/labor ratio either.
} 
where unitary specificity does not depend on relative factor use.

\section{Equilibrium with technology choice}

How is equilibrium determined with technology choice? Suppose temporarily that any point on the technology menu were available. Then each factor would select the technology that maximizes its factor income in Joint Production, subject to the other factor being willing to participate. In other words, $x_{i}$ units of factor $i$ would choose

$$
x_{\neg i}=\arg \max _{x_{\neg i} \geq 0}\left\{w_{i}^{n}\left(x_{k}, x_{l}\right) x_{i} \quad \text { s.t. } \quad w_{\neg i}^{n}\left(x_{k}, x_{l}\right) \geq p_{\neg i}\right\}, \quad i=1,2
$$

where $w_{i}^{n}\left(x_{k}, x_{l}\right)$ and $w_{\neg i}^{n}\left(x_{k}, x_{l}\right)$ are given by (8)-(9). As we discuss below, optimization together with equilibrium free entry determine the technology that new production units - if given the choice - would select from the technological menu. The question is, will that technology be actually developed? We do not model in any detail the process of technological development and adoption. Instead, we rely on a simple long-run principle: if there is unanimity in all new production relationships about a single technology, then that technology will be developed. Since all new production relationships in our model are identical, they would select the same technology and, according to the "unanimity" principle, that technology will be developed.

With this in mind, we define an (interior) incomplete-contracts equilibrium with technology choice as a set of variables $\left(x_{1}, x_{2}, C, E, E_{1}, E_{2}, p_{1}, p_{2}, w_{1}^{n}, w_{2}^{n}, \underline{y}^{o}\right)$ that satisfy technology-choice problems (28), the normalization $x_{1}=1$, as well as the conditions for an (interior) incomplete-contracts equilibrium. We define an (interior) efficient equilibrium with technology choice in the same manner.

As stated in proposition 13 below, there will still be some parameter configurations for which specificity is balanced in equilibrium and other configurations for which one of the factors appropriates the other and experiences market segmentation. Section 6.5 of the appendix shows that, in the first case, technology is determined in equilibrium by the joint free-entry conditions of the two factors (the first-order conditions for (28) generally serving to identify the constraints' shadow price). In the second case, technology is determined by the first-order condition of the appropriated factor:

Proposition 11 (Appropriation and Technology) Suppose that factor $i$ is appropriated (i.e., $\Delta_{i}>0$ ) in an incomplete-contracts equilibrium with technology choice. Then the 
equilibrium choice of technology $x_{k} / x_{l}$ is determined exclusively by factor $i$ 's unconstrained optimization problem $\max _{x_{\neg i} \geq 0}\left\{w_{i}^{n}\left(x_{k}, x_{l}\right) x_{i}\right\}$, given equilibrium $p_{k}$ and $p_{l}$.

The intuition behind proposition 11 is simple. Since its free-entry condition holds with equality, the appropriated factor $i$ breaks even with its optimal technology and would suffer a loss with any other technology. The other factor has therefore no choice but to accept factor $i$ 's preferred technology. ${ }^{25}$ Although different in that it is purely a marketequilibrium outcome, this result is akin to the idea in the property-rights literature that control rights are often optimally deposited with the agent who must make the largest specific investment (see, e.g., Grossman and Hart 1986; Dow 1993).

Before characterizing equilibrium with technology choice, we address the question of existence and uniqueness:

Proposition 1' (Existence and Uniqueness) An incomplete-contracts equilibrium with technology choice exists, is unique, and satisfies $C, E_{i}, U_{i}>0, i=1,2$. An efficient equilibrium with technology choice exists, is unique, and satisfies $C^{*}, E_{i}^{*}, U_{i}^{*}>0, i=1,2$.

\section{Exclusion and withdrawal}

The problem of appropriability can cause an inefficient technology to be chosen. It is simple to see that, because we have assumed full symmetry between the two factors, the efficient choice of technology has $x_{k} / x_{l}=1$. With incomplete contracts, this capital/labor ratio is generally distorted:

Proposition 12 (Exclusion and Withdrawal) Suppose the economy initially has balanced specificity and the efficient technology $x_{k} / x_{l}=1$. An institutional shift against factor $i$ takes place, causing $\bar{\phi}_{i}>\bar{\phi}_{\neg i}$. Define the "short-run" response (superscript "s.r.") as the incomplete-contracts equilibrium outcome with fixed technology $\left(x_{k} / x_{l}=1\right)$; and the "long-run" response (superscript ' '.r.") as the incomplete-contracts equilibrium outcome with technology choice.

(i) If $\mu=1$, then

$$
\frac{x_{i}^{l . r .}}{x_{\neg i}^{l . r .}}>\frac{x_{i}^{s . r .}}{x_{\neg i}^{s . r .}} \quad \text { and } \quad E_{\neg i}^{l . r .}<E_{\neg i}^{s . r .}
$$

(ii) If $\mu=0$, then

$$
\frac{x_{i}^{l . r .}}{x_{\neg i}^{l . r .}}<\frac{x_{i}^{s . r .}}{x_{\neg i}^{s . r .}} \quad \text { and } \quad E_{\neg i}^{l . r .}>E_{\neg i}^{s . r .}
$$

\footnotetext{
${ }^{25}$ Technically, "constraint qualification" is not satisfied for factor $\neg i$ 's optimization problem. The associated first-order condition is therefore not necessary.
} 
Let factor $i$ (capital, for concreteness) experience a detrimental shift in specificity parameters - i.e., a increase in $\bar{\phi}_{i}$ or a decrease $\bar{\phi}_{\neg i}$. From proposition 3 , we know that the short-run response with fixed technology is under-employment: $E_{i}^{\text {s.r. }}$ and $E_{\neg i}^{\text {s.r. are lower }}$ than efficient and the capital/labor ratio $x_{i}^{s . r .} / x_{\neg i}^{s . r .}=1$ remains fixed. In the long run, an inefficient technology will be chosen. In the base case $\mu=1$, capital will be substituted for labor leading to an inefficiently high capital/labor ratio $x_{i}^{l . r .} / x_{\neg i}^{l . r .}$. The partial "exclusion" of labor from Joint Production exacerbates its under-employment $\left(E_{\neg i}^{l . r .}<E_{\neg i}^{s . r .}\right)$, and can also be shown to alleviate the underemployment of capital $\left(E_{i}^{l . r .}>E_{i}^{s . r .}\right) \cdot{ }^{26}$ Excluding labor helps reduce the net specificity of each unit of capital, and reduce appropriable rents. By contrast, if unitary specificity did not depend on relative factor use, as is the case when $\mu=0$, then the opposite would happen. The capital/labor ratio would be inefficiently low, as capital "withdraws" from Joint Production in an attempt to capture a bigger piece of quasi-rents per own unit.

The rationale behind exclusion and withdrawal in proposition 12 can be made clearer if we use the accounting identity $y^{n}=w_{k}^{n} x_{k}+w_{l}^{n} x_{l}$ together with (21) to rewrite the objective function in (28) for appropriated factor $i$ as

$$
w_{i}^{n}\left(x_{k}, x_{l}\right) x_{i}=\left[y^{n}\left(x_{k}, x_{l}\right)-p_{\neg i} x_{\neg i}\right]-\Delta_{i}\left(x_{k}, x_{l}\right),
$$

where $\Delta_{i}\left(x_{k}, x_{l}\right)$ is given by (13). The first term expresses $i$ 's objective function from a social point of view (i.e., based on the other factor's social shadow cost $p_{\neg i}$ ); the second term - net effective specificity - captures the private distortion to that objective function due to rent appropriation. How does the second term distort the resulting technology? If $\mu=1$, it is easy to see that the effect of changing factor proportions on net specificity is given by $\partial \Delta_{i} / \partial x_{\neg i}>0$. Excluding the other factor helps reduce net effective specificity. If $\mu=0$, the opposite would hold. In both cases rent appropriation is reduced, but replaced by a problem of distorted capital/labor ratio.

This analysis of the technological response to rent appropriation can shed light on some aspects of high unemployment in Europe. The rise of unemployment in the 1970s is generally considered a result of oil shocks and of the productivity slowdown on economies that had developed labor-market institutions better adapted to an era of rapid growth. Wage

\footnotetext{
${ }^{26}$ In fact, with our assumption of infinite elasticity of factor substitution, technology choice will cause capital to be over-employed compared to the efficient outcome. But this result is not robust, and would disappear for lower elasticities of substitution.
} 
resistance to adjustment caused an increase in the labor share of national incomes and a contraction in employment. In the 1980s the labor share reversed its course and declined sharply, but unemployment kept rising (see, e.g., Blanchard and Katz 1996). The labor share of value added in French manufacturing, for example, rose from 61 to 68 percent in the 1970s, but then declined to 58 percent by the end of the 1980s. One plausible driving force behind this phenomenon is a technological response to appropriability characterized by labor exclusion: As capital is substituted for labor, the labor share declines while unemployment rises. Looking again at the example of France, one finds evidence of strong capital/labor substitution. Between 1970 and 1990, the capital/labor ratio in French manufacturing increased by 122 percent versus 88 percent in the US. Normalized by the capital labor ratio in the trade sector, the increase was 25 percent in France versus 8 percent in the US. ${ }^{27}$

\section{Balanced-specificity region}

As does institutional development, the introduction of technologies with new factor-intensity characteristics may help balance specificity and eliminate market segmentation in the long run. The following proposition characterizes the region in the space of specificity parameters $\left(\bar{\phi}_{k}, \bar{\phi}_{l}\right)$ in which effective specificity is balanced with technology choice.

Proposition 13 (Balanced-Specificity Region) For the incomplete-contracts equilibrium with technology choice, define the "efficient" set $\mathcal{E} \subseteq[0,1)^{2}$ as the set of parameters $\left(\bar{\phi}_{k}, \bar{\phi}_{l}\right)$ for which equilibrium is efficient; and define the "balanced-specificity" set $\mathcal{B}$ $\subseteq[0,1)^{2}$ as the set of parameters $\left(\bar{\phi}_{k}, \bar{\phi}_{l}\right)$ for which $\Delta=0$ in equilibrium.

(i) The efficient set $\mathcal{E}$ is the line $\bar{\phi}_{k}=\bar{\phi}_{l}$;

(ii) The balanced-specificity set includes, but is not generally equal to, the efficient set: If $\eta>1$, then $\mathcal{E} \subset \mathcal{B} \subset[0,1)^{2}$; if $\eta \leq 1$, then $\mathcal{E}=\left.\left.\mathcal{B}\right|_{\mu=1} \subset \mathcal{B}\right|_{\mu=0} \subset[0,1)^{2}$ (where " $\subset$ " denotes strict inclusion).

Statement (i) of the proposition identifies the efficient set $\mathcal{E}$ with the line $\bar{\phi}_{k}=\bar{\phi}_{l}$, which is intuitive since we have assumed everything else to be symmetric for the two factors. From proposition 2, we know that with fixed technology the balanced-specificity set would also correspond to a line. In the long run, technology choice can expand the possibilities of

\footnotetext{
${ }^{27}$ Another piece of evidence on labor shares that is consistent with the exclusion effect is the strong negative correlation observed between wage premia and the labor share of value added in US industry (see Krueger and Summers 1988, and Katz and Summers 1989). If part of the wage premium reflects specific quasi-rents, the associated low labor share may be the result of a labor exclusion response to rent appropriation.
} 
balanced specificity and turn the line into a broader cone, illustrated in figure $3 .{ }^{28}$ As stated in (ii), the balanced-specificity set $\mathcal{B}$ with technology choice can generally cover a region broader than the efficient line $\mathcal{E}$. The reason is that $\Delta$ can be reduced to zero through the adoption of technologies with suboptimal relative factor intensities. Technology choice is therefore another reason why analyzing the economy near a balanced-specificity point can be reasonable.

However, there are limits to the degree to which factor substitution allows specificity to be balanced in equilibrium. Going back to the objective function (29), using factor substitution to reduce rent appropriation $\Delta_{i}$ is costly for the efficiency term $y^{n}\left(x_{k}, x_{l}\right)-p_{\neg i} x_{\neg i}$. As factor substitution is relied on to offset appropriation, there may come a point where the resulting marginal inefficiency is greater than the marginal reduction in appropriation. For this reason the set $\mathcal{B}$ does not generally cover the full parameter space. Market segmentation can arise even with an infinite elasticity of factor substitution.

There is a sense in which balancing specificity is more difficult with factor exclusion than with withdrawal. This is because general-equilibrium forces offset the partial-equilibrium rebalancing effect of exclusion when $\mu=1$, while they reinforce the effect of withdrawal when $\mu=0$. Taking into account the general-equilibrium variables that determine net effective specificity $\Delta_{i}\left(x_{k}, x_{l} ; p_{k}, p_{l}\right)$ in (13), it is straightforward to see that $\partial \Delta_{i} / \partial p_{i}>0$ and $\partial \Delta_{i} / \partial p_{\neg i}<0$. Thus, if $i$ is the appropriated factor, the general-equilibrium effect of exclusion, which causes $p_{i}$ to rise and $p_{\neg i}$ to fall, is to increase $\Delta_{i}$ and partly offset its partial equilibrium effect when $\mu=1$. The general equilibrium effect of withdrawal on $p_{i}$ and $p_{\neg i}$ is the opposite, and helps reduce $\Delta_{i}$ further when $\mu=0$. Thus the former results in greater distortions in factor intensity than the latter.

A measure of the strength of the general equilibrium effect of exclusion on relative prices is how low the elasticity $\eta$ of factor supplies is. ${ }^{29}$ Consider the base case $\mu=1$. As the proposition states, when $\eta>1$, the balanced-specificity region $\mathcal{B}$ is greater than the efficient line $\mathcal{E}$; but when $\eta \leq 1$, region $\mathcal{B}$ coincides with $\mathcal{E}$. The strong general-equilibrium effect eliminates any possibility of balancing specificity outside the efficient line. In fact one can show that, in the case $\eta \leq 1$, the exclusion effect actually worsens segmentation of the appropriating factor $\neg i$ outside the efficient line, i.e. $w_{\neg i}^{l . r .}-p_{\neg i}^{l . r .}>w_{\neg i}^{s . r .}-p_{\neg i}^{s . r .}$ in the notation of proposition 12 . This is because, by (20), segmentation is equal to $\Delta / x_{\neg i}$, which

\footnotetext{
${ }^{28}$ Figure 3 was generated with $\eta=1.5$ and $\mu=1$.

${ }^{29}$ More generally, if $\eta_{k} \neq \eta_{t}$, the relevant measure of the strength of the general-equilibrium effect is how low a weighted average of the two factors' supply elasticities is.
} 


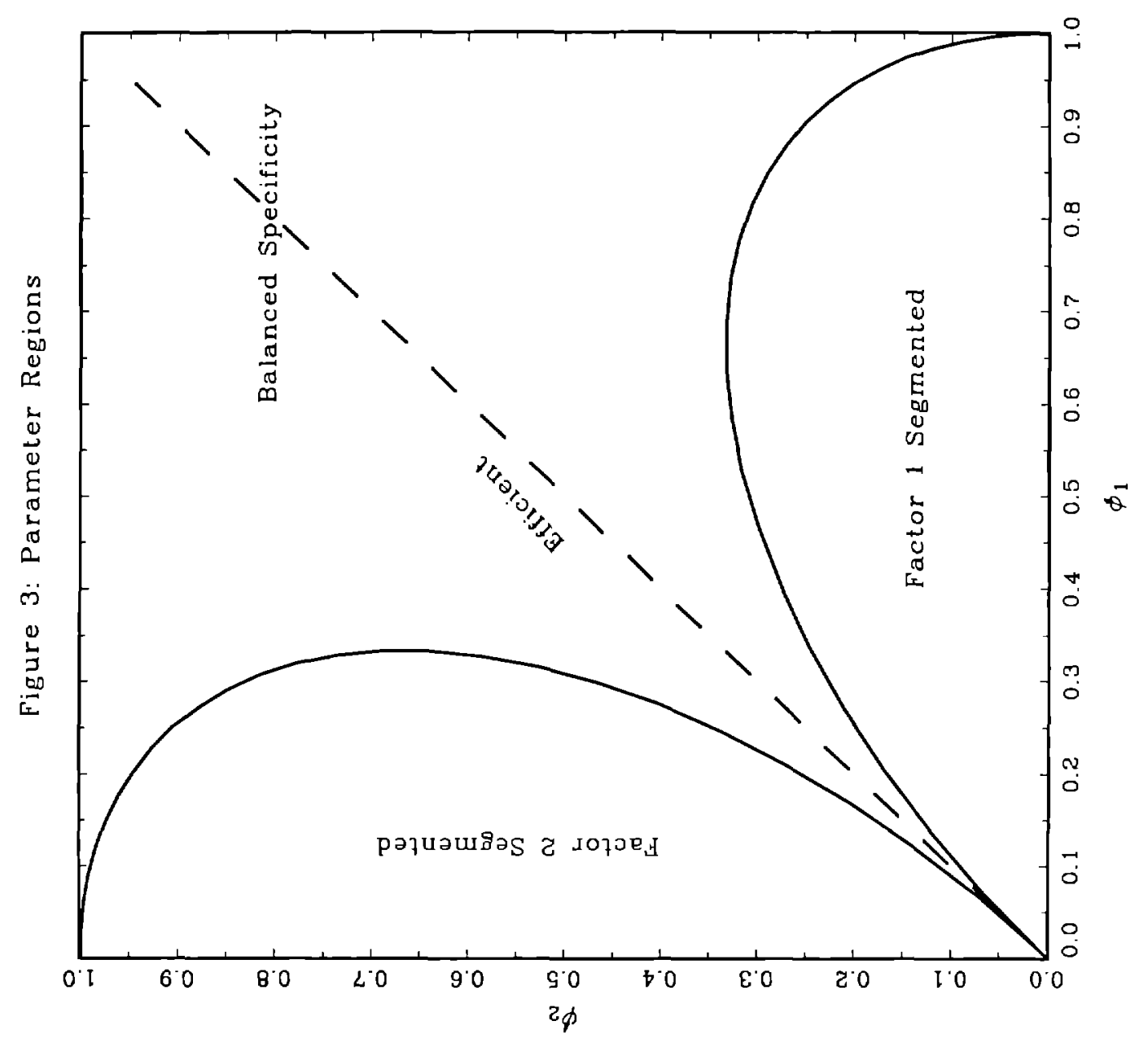


can rise when a strong general-equilibrium effect necessitates a great degree of exclusion (i.e., reduction of $x_{\neg i}$ ) to decrease $\Delta$. Thus, exclusion of the appropriating factor through technology choice not only leads to greater under-employment for that factor, but may also lead to greater factor segmentation.

\section{Conclusion}

The prevalence of specificity in economic relationships makes rent appropriation a prime suspect for a wide range of economic ills. In this paper we have tried to provide a simple, synthetic characterization of the multidimensional macroeconomic problem it gives rise to.

Why do economies waste unemployed resources during recessions? Why is there involuntary unemployment and labor market segmentation at all? Why do some economies "over-heat" at even modest levels of growth? Why do countries build social institutions that are later perceived as obstacles to flexible adjustment? Why do some countries seem stuck with a highly outdated productive structure? Why is the massive destruction of reforming countries' old productive systems not matched by immediate and significant creation? Why are methods of production (e.g., capital/labor ratios) so different across economies that are, otherwise, at a similar stage of development? Why do poor countries with cheap labor so often fail to attract capital and grow?

It is certainly not inconceivable that part of the answer to those apparently disconnected questions could be traced back to appropriable quasi-rents. As this paper argues, each of the phenomena those questions touch upon may reflect a different aspect of the economy's general-equilibrium response to widespread opportunism. 


\section{Appendix}

\subsection{Construction of Equilibrium in Section 2}

This section derives a constructive characterization of incomplete-contracts and efficient equilibria that will prove useful in what follows. An incomplete-contracts equilibrium is constructed in the following manner. First use equations (3) and (6) to define functions

$$
\widetilde{p}_{i}(E)=\left(x_{i} E\right)^{1 / \eta_{i}}, \quad i=1,2
$$

that give $p_{i}=\widetilde{p}_{i}(E)$ in equilibrium. $\tilde{p}_{i}(E)$ is continuous, strictly increasing, and takes values $\tilde{p}_{i}(0)=0$ and $\tilde{p}_{i}(+\infty)=+\infty$. Now free-entry condition (14), which is equivalent to (12), can be written as

$$
y^{n} \geq \max _{i=1,2}\left\{\left(1+\phi_{i}\right) \widetilde{p}_{i}(E) x_{i}+\left(1-\phi_{\neg i}\right) \widetilde{p}_{\neg i}(E) x_{\neg i}\right\} \equiv f(E)
$$

Given that $0 \leq \phi_{j} \leq 1, j=1,2$, it is clear that the function $f(E)$ inherits the above properties of $\tilde{p}_{i}(E)$ : it is continuous, strictly increasing, and takes values $f(0)=0$ and $f(+\infty)=+\infty$. Since $y^{n}>0$, this implies that free-entry condition (31) taken with equality yields a unique positive value of $E$. It is easy to check that the other equilibrium variables $\left(C, E_{1}, E_{2}, p_{1}, p_{2}, w_{1}^{n}, w_{2}^{n}, \underline{y}^{o}\right)$ are determined uniquely as a function of $E$ from the remaining equilibrium conditions.

Free-entry condition (14) can also be thought of as relating employment $E=\tilde{E}(\Delta)$ to net specificity - a relation that will prove useful. The function $\widetilde{E}(\Delta)$ is implicitly defined by

$$
y^{n}=\widetilde{p}_{1}(\widetilde{E}) x_{1}+\widetilde{p}_{2}(\widetilde{E}) x_{2}+\Delta
$$

It is continuous and strictly decreasing.

An efficient equilibrium corresponds to an incomplete-contracts equilibrium with a configuration of $\left(\phi_{1}, \phi_{2}\right)$ that yields $\Delta=0$ (which includes the configuration $\phi_{1}=\phi_{2}=0$ ). To see this, one can first easily check that the definition of an efficient equilibrium corresponds to that of an incomplete-contracts equilibrium if $\Delta=0$. In particular, the function $\widetilde{E}(\Delta)$ defined above takes value $E^{*}$ when $\Delta=0$. Conversely, $\Delta=0$ is necessary for an 
incomplete-contracts equilibrium to be efficient because, since $\widetilde{E}(\Delta)$ is strictly decreasing, $\widetilde{E}(\Delta) \neq E^{*}$ if $\Delta \neq 0$.

\subsection{Proofs of Propositions in Section 2}

Proof of proposition 1: The existence and uniqueness of an incomplete-contracts equilibrium was shown by construction in section 6.1. It was also shown that an efficient equilibrium corresponds to an incomplete-contracts equilibrium with $\phi_{1}=\phi_{2}=0$ (among other possible $\left(\phi_{1}, \phi_{2}\right)$-configurations), which therefore guarantees existence and uniqueness. It remains to be shown that $C, E_{i}, U_{i},>0, i=1,2\left(C^{*}, E_{i}^{*}, U_{i}^{*}>0\right.$ follows by setting $\phi_{1}=\phi_{2}=0$ ).

First, we show that $C>0$, for which, by (2), it is sufficient to show that $E>E^{o}$. Define the function

$$
g(E) \equiv x_{1}^{1+1 / \eta_{1}} E^{1 / \eta_{1}}+x_{2}^{1+1 / \eta_{2}} E^{1 / \eta_{2}}+\max \left\{x_{1}^{1+1 / \eta_{1}} E^{1 / \eta_{1}}, x_{2}^{1+1 / \eta_{2}} E^{1 / \eta_{2}}\right\}
$$

One can easily show that $g(E)>f(E)$ (defined in $(31)$ ) and $g^{\prime}(E), f^{\prime}(E)>0$, for all $E$. Since $z_{E}$ is defined in assumption 1 as the solution to $y^{n}=g\left(z_{E}\right)$ and equilibrium employment is the solution to $y^{n}=f(E)$, we must have $z_{E}<E$. Thus $E^{o}<z_{E}$ in assumption 1 implies $E^{o}<E$.

Second, $E_{i}=x_{i} E>0$ follows from $E>0$, which was shown in section 6.1. Third, to show that $U_{i}=1-E_{i}>0$, we show that $z_{y}$ in assumption 1 is the minimum value of $y^{n}$ for which the efficient equilibrium exhibits zero Autarky employment $\left(E_{i}=1\right)$ for one of the factors. To see this, note that, by substituting (30) in (10) (taken with equality), the minimum $y^{n}$ for which $E_{i}^{*}=1$ is

$$
x_{i}\left(1+\left(\frac{x_{\neg i}}{x_{i}}\right)^{1+1 / \eta_{i}}\right) .
$$

$z_{y}$ is simply the minimum of the above expression for $i=1,2$. Thus $y^{n}<z_{y}$ in assumption 1 implies $E_{i}^{*}<1$. Since proposition 3 (proved below) states that $E_{i} \leq E_{i}^{*}$, this implies $E_{i}<1$.

Proof of proposition 2: The first part of the proposition - that an incomplete-contracts equilibrium is efficient iff $\Delta=0-$ was proved in section 6.1 . What we still need to show is that this is equivalent to parameter condition (19). Solving (10) and (18) simultaneously 
for $\left(p_{1}, p_{2}\right)$, we get

$$
p_{i}=\frac{\phi_{\neg i}}{\phi_{1}+\phi_{2}} \frac{y^{n}}{x_{i}}, \quad i=1,2 .
$$

If we replace this expression for $p_{i}$ in (6) and use the fact that $E_{1} / x_{1}=E_{2} / x_{2}$ (see equation (3)), we obtain condition (19) in the proposition.

Proof of proposition 3: Recall from section 6.1 that $E=\widetilde{E}(\Delta)$ in equilibrium, and that $\widetilde{E}^{\prime}(\Delta)<0$ and $\widetilde{E}(0)=E^{*}$. This implies that an inefficient incomplete-contracts equilibrium, in which $\Delta>0$ by proposition 2 , must have $E=\widetilde{E}(\Delta)<\widetilde{E}(0)=E^{*}$. By (3), this implies that $E_{i}<E_{i}^{*}, i=1,2$.

Proofs of propositions 4 and 5: Given in the main text.

Proof of proposition 6: Differentiating (23) with respect to $C$ and $\underline{y}^{o}$ yields

$$
\begin{gathered}
\frac{\partial W}{\partial C}=y^{n}-p_{1} x_{1}-p_{2} x_{2} \\
\frac{\partial W}{\partial \underline{y}^{o}}=-D^{\prime}\left(\underline{y}^{o}\right)\left(\underline{y}^{o}-p_{1} x_{1}-p_{2} x_{2}\right) .
\end{gathered}
$$

By (14) taken with equality, the first expression is equal to $\Delta$, which is positive in an inefficient equilibrium (by proposition 2). By (16), the second expression is equal to $-D^{\prime}\left(\underline{y}^{o}\right)\left[\lambda_{1}\left(w_{1}^{n}-p_{1}\right)+\lambda_{2}\left(w_{2}^{n}-p_{2}\right)\right]$, which is negative in an inefficient equilibrium (by proposition 4 and $\left.\lambda_{1}, \lambda_{2}>0\right)$.

Proof of proposition 7: Taking (21) into account, the equilibrium entry and exit conditions with subsidies are

$$
\begin{gathered}
y^{n}+\sigma^{n}=p_{1} x_{1}+p_{2} x_{2}+\Delta ; \\
\underline{y}^{o}+\sigma^{o}=p_{1} x_{1}+p_{2} x_{2}+\lambda_{\neg i} \Delta,
\end{gathered}
$$

where $\neg i$ denotes the appropriating factor. Substituting the efficient entry and exit conditions $\left((10)\right.$ with equality and (17)) for $y^{n}$ and $\underline{y}^{o}$ in the formulae above, and replacing $\sigma^{n}$ and $\sigma^{\circ}$ for their proposed expressions, transforms the equilibrium conditions into

$$
\begin{gathered}
0=\left(p_{1}-p_{1}^{*}\right) x_{1}+\left(p_{2}-p_{2}^{*}\right) x_{2}+\left(\Delta-\Delta^{*}\right), \\
0=\left(p_{1}-p_{1}^{*}\right) x_{1}+\left(p_{2}-p_{2}^{*}\right) x_{2}+\left(\lambda_{\neg i} \Delta-\lambda_{\neg i}^{*} \Delta^{*}\right),
\end{gathered}
$$

which are obviously satisfied for $E=E^{*}$. 


\subsection{Proofs of Propositions in Section 3}

Proof of proposition 8: From condition (19) for efficiency, we solve for $y^{n b}$ :

$$
y^{n b}=\left(\phi_{l}+\phi_{k}\right)\left(\frac{\phi_{l}^{\eta_{k}} x_{l}^{1+\eta_{l}}}{\phi_{k}^{\eta_{l}} x_{k}^{1+\eta_{k}}}\right)^{1 /\left(\eta_{l}-\eta_{k}\right)}>0 .
$$

To determine which factor is segmented, rewrite (13) in terms of functions (30): $\Delta_{k}=$ $\phi_{k} x_{k} \widetilde{p}_{k}(E)-\phi_{l} x_{l} \widetilde{p}_{l}(E)$. By differentiating this expression at a point where $\Delta_{k}=0$, we get

$$
\left.\frac{d \Delta_{k}}{d E}\right|_{\Delta_{k}=0}=\left(\frac{1}{\eta_{k}}-\frac{1}{\eta_{l}}\right) \phi_{k} x_{k} p_{k}(E)
$$

which is negative given that $\eta_{k}>\eta_{l}$. Noting that $E$ is an increasing function of $y^{n}$ (which follows immediately from equation $y^{n}=f(E)$ in section 6.1 ), and that $\Delta_{k}=0$ at the unique value for $y^{n}=y^{n b}$, we get $\Delta_{k}>0$ (i.e., the labor market is segmented by proposition 4) when $y^{n}<y^{n b}$; and $\Delta_{k}<0$ (i.e., the capital market is segmented) when $y^{n}>y^{n b}$.

Proof of proposition 9: Suppose that $y^{n} \neq y^{n b}$ and that $i$ is the appropriated factor. Then free-entry condition (12) holds with equality for factor $i$. Substituting functions (30) for the $p_{j}$ 's and totally differentiating with respect to $E$ and $y^{n}$, we get

$$
\frac{d y^{n}}{y^{n}}=\frac{1}{y^{n}}\left[\frac{1}{\eta_{i}}\left(1+\phi_{i}\right) p_{i} x_{i}+\frac{1}{\eta_{\neg i}}\left(1-\phi_{\neg i}\right) p_{\neg i} x_{\neg i}\right] \frac{d E}{E} .
$$

The corresponding equation for the efficient equilibrium is obtained by setting $\phi_{i}=\phi_{\neg i}=0$. Comparing those two equations, it is clear that

$$
\xi_{y^{n}}^{E^{*}} \equiv \frac{d E^{*} / E}{d y^{n} / y^{n}}<\xi_{y^{n}}^{E} \equiv \frac{d E / E}{d y^{n} / y^{n}}
$$

if and only if

$$
\frac{1}{\eta_{i}} p_{i}^{*} x_{i}+\frac{1}{\eta_{\neg i}} p_{\neg i}^{*} x_{\neg i}>\frac{1}{\eta_{i}}\left(1+\phi_{i}\right) p_{i} x_{i}+\frac{1}{\eta_{\neg i}}\left(1-\phi_{\neg i}\right) p_{\neg i} x_{\neg i},
$$

which, after a few algebraic steps, is equivalent to

$$
\left(\frac{1}{\eta_{\neg i}}-\frac{1}{\eta_{i}}\right)\left[p_{\neg i}^{*}-\left(1-\phi_{\neg i}\right) p_{\neg i}\right] x_{\neg i}>\frac{1}{\eta_{i}}\left[\left(1+\phi_{i}\right) p_{i} x_{i}+\left(1-\phi_{\neg i}\right) p_{\neg i} x_{\neg i}-p_{i}^{*} x_{i}-p_{\neg i}^{*} x_{\neg i}\right]=0 .
$$

The right-hand side of the above inequality is zero, because it is equal to the difference 
between the right-hand sides of the inefficient and efficient free-entry conditions, (14) and (10). The sign of the left-hand side is the sign of $1 / \eta_{\neg i}-1 / \eta_{i}$, since $E_{\neg i}^{*}>E_{\neg i}$ (proposition 3) implies $p_{\neg i}^{*}>p_{\neg i}$ by (30). Thus, if appropriated factor $i$ is capital - i.e., labor is segmented - then $\eta_{\neg i}<\eta_{i}$, inequality (32) holds, and $\xi_{y^{n}}^{E^{*}}<\xi_{y^{n}}^{E}$; if, on the contrary, capital is segmented, then $\eta_{\neg i}>\eta_{i}$ and $\xi_{y^{n}}^{E^{*}}>\xi_{y^{n}}^{E}$.

\subsection{Proof of the Proposition in Section 4.1}

Proof of proposition 10: (i) Factor $i$, aggregate income (27) can be written as a function of the other factor's net specificity $\Delta_{i}$ :

$$
W_{i}\left(\Delta_{\neg i}\right)=\max \left\{\Delta_{\neg i}, 0\right\} x_{i} \tilde{E}\left(\left|\Delta_{\neg i}\right|\right)+\widetilde{p}_{i}\left(\widetilde{E}\left(\left|\Delta_{\neg i}\right|\right)\right)
$$

taking into account (3), (21), and the definitions of $\widetilde{p}_{i}($.$) and \widetilde{E}($.$) in section 6.1. Since$ $\vec{p}_{i}^{\prime}>0$ and $\widetilde{E}^{\prime}<0$, it is clear that $W_{i}(0)>W_{i}\left(\Delta_{\neg i}\right)$ for any $\Delta_{\neg i}<0$. So $W_{i}\left(\Delta_{\neg i}\right)$ is maximized for a non-negative value $\widehat{\Delta}_{\neg i}^{[i]}$ of $\Delta_{\neg i}$-- i.e., net effective specificity in favor of factor $i$. By definition (13),

$$
\Delta_{\neg i}=\phi_{\neg i} \tilde{p}_{\neg i}\left(\widetilde{E}\left(\left|\Delta_{\neg i}\right|\right)\right) x_{\neg i}-\phi_{i} \tilde{p}_{i}\left(\tilde{E}\left(\left|\Delta_{\neg i}\right|\right)\right) x_{i}
$$

which defines a line in parameter space if we fix $\Delta_{\neg i}=\widehat{\Delta}_{\neg i}^{[i]}$.

(ii) For a unit of factor $i$ employed in Autarky, ex-post income $p_{i}=\widetilde{p}_{i}\left(\tilde{E}\left(\left|\Delta_{\neg i}\right|\right)\right)$ is maximized at the efficient value of $\Delta_{\neg i}=0$, again because $\widetilde{p}_{i}^{\prime}>0$ and $\widetilde{E}^{\prime}<0$. For a unit employed in Joint Production, we show that ex-post income $w_{i}^{n}$ is always increasing with $\Delta_{\neg i}$ (which, it is easy to see from (33), is increasing with $\phi_{\neg i}$ and decreasing with $\phi_{i}$ ). If $\Delta_{\neg i}<0$, we know by proposition 4 that $w_{i}^{n}=p_{i}=\tilde{p}_{i}\left(\widetilde{E}\left(\left|\Delta_{\neg i}\right|\right)\right)$, which increases with $\Delta_{\neg i}$ when the latter is negative. If $\Delta_{\neg i} \geq 0$, we know by proposition 4 that $w_{\neg i}^{n}=p_{\neg i}$. Using the accounting identity $y^{n}=w_{i}^{n} x_{i}+w_{\neg i}^{n} x_{\neg i}$, we write $w_{i}^{n}=\left(y^{n}-\tilde{p}_{\neg i}\left(\widetilde{E}\left(\left|\Delta_{\neg i}\right|\right)\right) x_{\neg i}\right) / x_{i}$, which is always increasing with $\Delta_{\neg i}$ when the latter is non-negative.

\subsection{Mathematical Appendix to Section 4.2}

This appendix provides a proof for propositions 11, 12,13, and 1', in that order. Equilibrium with technology choice involves an additional endogenous variable $x_{k} / x_{l}$ (equilibrium $x_{l}$ being normalized to 1 ) and optimization problem (28) for factors $i=k, l$. If the constraint qualification condition is satisfied for this problem - i.e., $w_{\neg i}^{n}\left(x_{k}, x_{l}\right)>p_{\neg i}$ for some feasible 
value of $x_{\neg i}$ - then the following first-order condition is necessary:

$$
\frac{\partial\left(w_{i}^{n} x_{i}\right)}{\partial x_{\neg i}}+\alpha_{i} \frac{\partial w_{\neg i}^{n}}{\partial x_{\neg i}}=0 \quad \text { and } \quad \alpha_{i}\left(w_{\neg i}^{n}-p_{\neg i}\right)=0, \quad \text { for some } \alpha_{i} \geq 0
$$

We divide the parameter space $\left(\bar{\phi}_{k}, \bar{\phi}_{l}\right) \in[0,1)$ into three sets: $\mathcal{A}_{i}, i=k, l$, corresponds to parameter configurations for which factor $i$ is appropriated (i.e., $\Delta_{i}>0$ ) in the incomplete-contracts equilibrium with technology choice; $\mathcal{B}$ corresponds to parameters for which equilibrium is characterized by balanced specificity $(\Delta=0)$.

Proof of Proposition 11: Suppose $\left(\bar{\phi}_{k}, \bar{\phi}_{l}\right) \in \mathcal{A}_{i}$. Proposition 4 shows that, with the equilibrium technology $x_{k} / x_{l}$, factor $i$ 's market clears and factor $\neg i$ 's market is segmented. This means that the constraint $w_{\neg i}^{n}>p_{\neg i}$ to factor $i$ 's technology-choice problem (28) is not binding in equilibrium. First-order condition (34) becomes

$$
\frac{\partial\left(w_{i}^{n} x_{i}\right)}{\partial x_{\neg i}}=\frac{1}{2}\left[\frac{a}{2}-\mu \bar{\phi}_{i}\left(\frac{x_{i}}{x_{\neg i}}\right)^{1-\mu} p_{i}-\left(1-(1-\mu) \bar{\phi}_{\neg i}\left(\frac{x_{i}}{x_{\neg i}}\right)^{\mu}\right) p_{\neg i}\right]=0
$$

taking (8)-(9) and assumption 4 into account. It determines technology $x_{k} / x_{l}$ given equilibrium $p_{k}$ and $p_{l}$.

Is this technology consistent with factor $\neg i$ 's technology choice problem? Since factor $i$ 's market clears $\left(w_{i}^{n}-p_{i}=0\right)$ at this (unconstrained) optimum technology, no other technology can yield a positive value for $w_{i}^{n}-p_{i}$. Therefore constraint qualification for factor $\neg i$ 's problem does not hold, and the associated first-order conditions are not necessary.

We can now determine equilibrium quantities (and prices) in regions $\mathcal{A}_{k}, \mathcal{A}_{k}$, and $\mathcal{B}$. Suppose $\left(\bar{\phi}_{k}, \bar{\phi}_{l}\right) \in \mathcal{A}_{i}$. Given technology, equilibrium employment is determined - as in section 2 - by appropriated factor $i$ 's free-entry condition. Multiplying each side of (14) (taken with equality) by $E$ after taking assumption 4 into account, and using (3) and (6), yields

$$
\frac{a}{2}\left(E_{i}+E_{\neg i}\right)=\left(1+\bar{\phi}_{i}\left(\frac{x_{\neg i}}{x_{i}}\right)^{\mu}\right) E_{i}^{1+1 / \eta}+\left(1-\bar{\phi}_{\neg i}\left(\frac{x_{i}}{x_{\neg i}}\right)^{\mu}\right) E_{\neg i}^{1+1 / \eta} .
$$

Since (3) implies $x_{i} / x_{\neg i}=E_{i} / E_{\neg i},(35)$ and (36) can be solved simultaneously to yield equilibrium quantities in region $\mathcal{A}_{i}$ :

$$
\begin{aligned}
& \text { If } \mu=1, \quad E_{i}=\left(\frac{a}{2} \frac{1+\bar{\phi}_{\neg i}}{1+\bar{\phi}_{i} \bar{\phi}_{\neg i}}\right)^{\eta} \text { and } \quad E_{\neg i}=\left(\frac{a}{2} \frac{1-\bar{\phi}_{i}}{1+\bar{\phi}_{i} \bar{\phi}_{\neg i}}\right)^{\eta} ; \\
& \text { if } \mu=0, \quad E_{i}=\left(\frac{a}{2} \frac{1}{1+\bar{\phi}_{i}}\right)^{\eta} \quad \text { and } \quad E_{\neg i}=\left(\frac{a}{2} \frac{1}{1-\bar{\phi}_{\neg i}}\right)^{\eta} \text {. }
\end{aligned}
$$


Suppose now that $\left(\bar{\phi}_{k}, \bar{\phi}_{l}\right) \in \mathcal{B}$. The two factors' free-entry conditions hold then with equality (and are equivalent). They can be used to determine equilibrium quantities $E_{k}$ and $E_{l}$. Multiplying both sides of the balanced-specificity condition $\phi_{k} p_{k} x_{k}=\phi_{l} p_{l} x_{l}$ by $E$, and taking (3), (6), and assumption 4 into account, we get

$$
E_{i} / E_{\neg i}=\psi_{i}, \quad \text { where } \quad \psi_{i}= \begin{cases}\left(\bar{\phi}_{\neg i} / \bar{\phi}_{i}\right)^{\frac{1}{1+1 / \eta-2 \mu}}, & \text { if } \bar{\phi}_{i} \bar{\phi}_{\neg i} \neq 0 \text { and } 1+1 / \eta-2 \mu \neq 0 \\ 1, & \text { otherwise }\end{cases}
$$

for $i=k, l .{ }^{30}$ We can use this expression to solve for $E_{i}$ in free-entry condition (14) (taken with equality and $\Delta=0$ ), again after multiplying both sides by $E$ and taking (3), (6), and assumption 4 into account:

$$
E_{i}=\left(\frac{a}{2} \frac{1+\psi_{\neg i}}{1+\psi_{\neg i}^{1+1 / \eta}}\right)^{\eta}, \quad i=k, l
$$

Because the constraints to technology choice problem (28) are binding in $\mathcal{B}$, the associated first-order conditions (34) determine the constraints' shadow prices $\alpha_{i}$. For the first-order conditions to hold, we need to check that $\alpha_{i} \geq 0$. Since the line $\bar{\phi}_{k}=\bar{\phi}_{l}$ is always in $\mathcal{B}$, it is sufficient by continuity to check $\alpha_{i} \geq 0$ on that line. To do so, we use expression (35) for $\partial\left(w_{i}^{n} x_{i}\right) / \partial x_{\neg i}$ and a similarly derived expression for $\partial w_{\neg i}^{n} / \partial x_{\neg i}$ :

$$
\frac{\partial w_{\neg i}^{n}}{\partial x_{\neg i}}=\frac{1}{2 x_{\neg i}}\left[-\frac{a}{2} \frac{x_{i}}{x_{\neg i}}+\left(1-(1-\mu) \bar{\phi}_{i}\left(\frac{x_{i}}{x_{\neg i}}\right)^{-\mu}\right) p_{i} \frac{x_{i}}{x_{\neg i}}+\mu \bar{\phi}_{\neg i}\left(\frac{x_{i}}{x_{\neg i}}\right)^{\mu} p_{\neg i}\right] .
$$

Since both factors are symmetric when $\bar{\phi}_{k}=\bar{\phi}_{l}$, it is easy to see - using $a / 2=p_{i}=p_{\neg i}$ under symmetry (by (14) with $\Delta=0$ ) - that

$$
\frac{\partial\left(w_{i}^{n} x_{i}\right)}{\partial x_{\neg i}}=-\frac{\partial w_{\neg i}^{n}}{\partial x_{\neg i}} x_{\neg i}
$$

in that case. It follows immediately from (34) that $\alpha_{i} \geq 0$.

Proof of proposition 12: Suppose parameters shift against factor $i$ so that $\bar{\phi}_{i}>\bar{\phi}_{\neg i}$. In the short run with fixed technology $E_{k} / E_{l}=1,(6)$ and (14) (with equality) determine equilibrium quantities:

$$
E_{i}^{s . r .}=E_{\neg i}^{s . r .}=\left(\frac{a}{2+\bar{\phi}_{i}-\bar{\phi}_{\neg i}}\right)^{\eta}
$$

\footnotetext{
${ }^{30}$ Note that if $1+1 / \eta-2 \mu=0$, then $\left(\bar{\phi}_{k}, \bar{\phi}_{l}\right) \in \mathcal{B}$ iff $\bar{\phi}_{k}=\bar{\phi}_{l}$. This justifies the value $\psi_{i}=1$ in that case.
} 
The proof of the proposition follows directly from comparing (40) with (37) if $\left(\bar{\phi}_{k}, \bar{\phi}_{l}\right) \in \mathcal{A}_{i}$, and with $(38)-(39)$ if $\left(\bar{\phi}_{k}, \bar{\phi}_{l}\right) \in \mathcal{B}$.

We now characterize the boundaries that delimit the different regions in parameter space. We start by determining all the "smooth" boundaries - i.e., boundaries at which equilibrium variables are continuous functions of the parameters $\left(\bar{\phi}_{k}, \bar{\phi}_{l}\right)$. Note first that any point that smoothly separates $\mathcal{A}_{k}$ and $\mathcal{A}_{l}$ must be included in $\mathcal{B}$ (otherwise the flip in factor-market segmentation would involve a discontinuity). We can therefore restrict our attention to smooth boundaries that separate region $\mathcal{B}$ from regions $\mathcal{A}_{i}, i=k, l$.

At any point $\left(\bar{\phi}_{k}, \bar{\phi}_{l}\right)$ along such a boundary, equilibrium must satisfy equations (37) and (39) simultaneously. Equating $E_{i} / E_{\neg i}$ as determined by each of those two equations, a smooth boundary must satisfy

$$
\bar{\phi}_{\neg i}=h_{\mu}\left(\bar{\phi}_{\neg i} / \bar{\phi}_{i}\right), \quad \text { where } \quad h_{1}(z) \equiv \frac{z^{-\frac{1}{\eta-1}}-1}{z^{-\frac{\eta}{\eta-1}}+1} \text { and } h_{0}(z) \equiv \frac{1-z^{\frac{1}{1+\eta}}}{1+z^{-\frac{\eta}{1+\eta}}}
$$

as long as $\bar{\phi}_{i} \bar{\phi}_{\neg i} \neq 0$ and $1+1 / \eta-2 \mu \neq 0$ (otherwise it must satisfy the continuous extension $\left.\bar{\phi}_{i}=\bar{\phi}_{\neg i}=0\right)$. In the space of parameters $\left(\bar{\phi}_{k}, \bar{\phi}_{l}\right) \in[0,1)$, such a boundary starts at the origin and must remain on the side of the 45 degree line where $\bar{\phi}_{i} \geq \bar{\phi}_{\neg i}$. Points between the 45 degree line and the boundary are in $\mathcal{B}$, and points between the boundary and the $\bar{\phi}_{i}$-axis are in $\mathcal{A}_{i}$. (If this were not so, then a point such as $\left(\bar{\phi}_{i}, \bar{\phi}_{\neg i}\right)=(1,0)$ would not be in $\mathcal{A}_{i}$.) It is easy to check that this configuration holds if $\mu=0$, or if $\mu=1$ and $\eta>0$ (a direct consequence of the fact that $h_{\mu}(z) \in[0,1)$ iff $0 \leq z<1$, in this case); and does not hold if $\mu=1$ and $\eta<0$ (in this case $h_{1}(z) \in[0,1)$ iff $z>1$ ). By symmetry, the set $\mathcal{A}_{\neg i}$ is a mirror image of $\mathcal{A}_{i}$.

Thus, if $\mu=0$, or $\mu=1$ and $\eta>0$, the set $\mathcal{B}$ lies between the two boundaries (41) for $i=k, l$, and is flanked by the sets $\mathcal{A}_{k}$ and $\mathcal{A}_{l}$ on each side. If $\mu=1$ and $\eta \leq 0$, no smooth boundaries exist (other than at the origin). The set $\mathcal{B}$ corresponds to the 45 degree line, and the sets $\mathcal{A}_{i}$ to the space between that line and the $\bar{\phi}_{i}$-axis.

Proof of proposition 13: Statement (i): Since the two factors are symmetric, a necessary condition for efficiency is a symmetric technology $x_{k} / x_{l}=1$. Looking at (39) and (37), it is clear that $E_{k} / E_{l}=1$ only if $\phi_{l}=\phi_{k}$. But $\phi_{l}=\phi_{k}$ is also a sufficient condition for efficiency, because, given the efficient technology, proposition 2 shows that equilibrium quantities are efficient. Thus the efficient set $\mathcal{E}$ corresponds to the line $\phi_{l}=\phi_{k}$.

Statement (ii) follows immediately from the above characterization of the different 
regions.

Proof of proposition 1': Existence of an incomplete-contracts equilibrium with technology choice was shown above by construction. Uniqueness follows from (i) the unique determination of regions $\mathcal{A}_{k}, \mathcal{A}_{l}$, and $\mathcal{B}$ (a point in region $\mathcal{A}_{k}$ cannot also be in region $\mathcal{A}_{l}$ because the two sets lie on opposite sides of the 45 degree line; and cannot be in $\mathcal{B}$ because the latter contains the 45 degree line, and smooth boundaries (41) are unique if they exist); and (ii) the unique determination of equilibrium variables in each of those regions (based on (37) for region $\mathcal{A}_{i}$ and on (39) for region $\mathcal{B}$ ).

We turn to the interior-equilibrium properties $C, E_{i}, U_{i}>0, i=k, l$. Because we have assumed that there are no pre-existing units (assumption 3), $C>0$ follows from $E_{i}>0$ by (2)-(3); and $E_{i}>0$ follows from $a>0$ in equations (37) (recalling that $\bar{\phi}_{i}<1$ ) and (39). $U_{i}=1-E_{i}>0$ follows from $a<1$ in equations (37) and (39) (noting that $\left(1+\psi_{\neg i}\right) /\left(1+\psi_{\neg i}^{1+1 / \eta}\right)$ cannot be greater than 2$)$.

The above existence, uniqueness, and interior-equilibrium properties also apply to an efficient equilibrium with technology choice, since it simply corresponds to the special parameter configuration $\phi_{l}=\phi_{k}$. 


\section{References}

[1] Acemoglu, Daron (1996): "A Microfoundation for Social Increasing Returns in Human Capital Accumulation," Quarterly Journal of Economics, 111(3), 779-804.

[2] Ball, Laurence (1996): "Disinflation and the NAIRU," NBER Working Paper No. 5520 , March.

[3] Becker, Gary (1964): Human Capital. New York: Columbia University Press.

[4] _ (1983): "A Theory of Competition Among Pressure Groups for Political Influence," Quarterly Journal of Economics, 98(3), 371-400.

[5] Binmore, K. G., Ariel Rubinstein, and A. Wolinsky (1986): "The Nash Bargaining Solution in Economic Modeling," Rand Journal of Economics, 17, 176-188.

[6] Blanchard, Olivier, and Juan F. Jimeno (1995): "Structural Unemployment: Spain Versus Portugal," American Economic Review, 85(2), 212-218.

[7] Blanchard, Olivier, and Lawrence F. Katz (1996): "The Natural Rate of Unemployment," typescript, June.

[8] Bulow, Jeremy I., and Lawrence H. Summers (1986): "A Theory of Dual Labor Markets with Application to Industrial Policy, Discrimination, and Keynesian Unemployment," Journal of Labor Economics, 4(3, pt. 1), 376-414.

[9] Caballero, Ricardo J., and Mohamad L. Hammour (1994): "The Cleansing Effect of Recessions," American Economic Review, 84, 1350-1368.

[10] - (1996a): "On the Timing and Efficiency of Creative Destruction," Quarterly Journal of Economics, 111(3), 805-852.

[11] _ (1996b): "On the Ills of Adjustment." Journal of Development Economics, forthcoming.

[12] (1996c): "Appropriability and the Business Cycle," work in progress.

[13] De Long, J. Bradford (1990): "Liquidation Cycles: Old Fashioned Real Business Cycle Theory and the Great Depression," NBER Working Paper No. 3546. 
[14] De Long, J. Bradford and Lawrence H. Summers (1988): "How does Macroeconomic Policy Affect Output?" Brookings Papers on Economic Activity, 1988(2), 433-495.

[15] Dow, Gregory K. (1993): "Why Capital Hires Labor: A Bargaining Perspective," American Economic Review, 83(1), 118-134.

[16] Grossman, Sanford J., and Oliver D. Hart (1986): "The Costs and Benefits of Ownership: A Theory of Vertical and Lateral Integration," Journal of Political Economy, 94(4), 691-719.

[17] Grout, Paul A. (1984): "Investment and Wages in the Absence of Binding Contracts: A Nash Bargaining Approach," Econometrica, March, 52(2), 449-460.

[18] Hall, Robert E., and Edward P. Lazear (1984): "The Excess Sensitivity of Layoffs and Quits to Demand," Journal of Labor Economics, 2(2), 233-257.

[19] Hart, Oliver (1995): Firms, Contracts, and Financial Structure, Oxford: Clarendon Press.

[20] Hart, Oliver, and John Moore (1990): "Property Rights and the Nature of the Firm," Journal of Political Economy, 98(6), 1119-1158.

[21] _ (1994): "A Theory of Debt Based on the Inalienability of Human Capital," Quarterly Journal of Economics, 109, 841-880.

[22] Katz, Lawrence F., and Lawrence H. Summers (1989), "Industry Rents: Evidence and Implications," Brookings Papers on Economic Activity, 1989(Microeconomics), 209-275.

[23] Krueger, Alan B., and Lawrence H. Summers (1988): "Efficiency Wages and the InterIndustry Wage Structure," Econometrica, 56, 259-293.

[24] Klein, Benjamin, Robert G. Crawford, and Armen A. Alchian (1978): "Vertical Integration, Appropriable Rents, and the Competitive Contracting Process," Journal of Law and Economics, October, 21(2), 297-326.

[25] Lindbeck, Assar, and Dennis Snower (1986): "Wage Setting, Unemployment and Insider Outsider Relations," American Economic Review, 76, 235-239.

[26] MacLeod, W. Bentley, and James M. Malcomson (1993): "Investments, Holdup, and the Form of Market Contracts," American Economic Review, 83(4), 811-837. 
[27] Makowski, Louis, and Joseph M. Ostroy (1995): "Appropriation and Efficiency: A Revision of the First Theorem of Welfare Economics," American Economic Review, $85(4), 808-827$.

[28] Myerson, Roger B., and Mark A. Satterthwaite (1983): "Efficient Mechanisms for Bilateral Trading," Journal of Economic Theory, 28, 265-281.

[29] North, Douglass C., and Barry R. Weingast (1989): "Constitutions and Commitment: The Evolution of Institutions Governing Public Choice in Seventeenth-Century England," Journal of Economic History, XLIX(4), 254-283.

[30] Phelps, Edmund S., and Sidney G. Winter, Jr. (1970): "Optimal Price Policy under Atomistic Competition," in E. S. Phelps et al., Microeconomic Foundations of Employment and Inflation Theory, New York: W.W. Norton.

[31] Ramey, Garey, and Joel Watson (1996): "Bilateral Trade and Opportunism in a Matching Market," UC San Diego Economics Discussion Paper 96-08, March.

[32] Robinson, James A. (1995): "Incomplete Contracting, Capital Accumulation, and Labor Market Institutions," typescript, December.

[33] _ (1996): "The Dynamics of Labor Market Institutions," typescript, July.

[34] Roe, M.J. (1994): Strong Managers, Weak Owners: The Political Roots of American Corporate Finance, Princeton, NJ: Princeton University Press.

[35] Rosenberg, Nathan (1965): "Adam Smith on the Division of Labour: Two Views or One?" Economica, 32(May), 127-139.

[36] Shaked, A., and J. Sutton (1984): "Involuntary Unemployment as a Perfect Equilibrium in a Bargaining Model," Econometrica, 52, 1351-1364.

[37] Shleifer, Andrei, and Robert W. Vishny (1995): "A Survey of Corporate Governance," Harvard Institute of Economic Research, Discussion Paper No. 1741, October.

[38] Sichel, Daniel E. (1992): "Inventories and the Three Phases of the Business Cycle," Economic Activity Working Paper no. 128, Board of Governors of the Federal Reserve System, August.

[39] Simons, Henry C. (1944): "Some Reflections on Syndicalism," Journal of Political Economy, 52, 1-25. 
[40] Thomas, Jonathan, and Tim Worrall (1994): "Foreign Direct Investment and the Risk of Expropriation," Review of Economic Studies, 61, 81-108.

[41] Topel, Robert (1990): "Specific Capital and Unemployment: Measuring the Costs and Consequences of Job Loss," Carnegie-Rochester Conference Series on Public Policy, $33,181-214$.

[42] Williamson, Oliver E. (1979): "Transaction-Cost Economics: The Governance of Contractual Relations," Journal of Law and Economics, October, 22 (2), 233-261.

[43] - (1985): The Economic Institutions of Capitalism, New York: Free Press.

[44] _ (1988): "Corporate Finance and Corporate Governance," Journal of Finance, XLIII(3), 567-591. 